\title{
El Castillo de León. Breve historia de un valor patrimonial
}

Emilio Morais Vallejo

Universidad de León

\begin{abstract}
RESUMEN. El Castillo de León es un monumento con una larga historia que empieza en la antigüedad y llega hasta nuestros días. Se construyó sobre la antigua muralla romana y en la Edad Media se configuró como castillo, siendo símbolo del poder real. Sufrió numerosas reformas hasta su abandono en el siglo XVIII. En el siglo XIX se convirtió en cárcel y en la centuria siguiente se transformó en Archivo Histórico después de una profunda restauración. A pesar de tantas vicisitudes, sigue teniendo el aspecto de una fortaleza medieval.

Palabras clave: Castillo, León, arquitectura militar, restauración, patrimonio.

ABSTRACT. The Castle of León is a monument with a long history which begins in the antiquity and continues up to the present day. It was built on the old Roman wall and, as a castle, became a symbol of the royal power in the Middle Ages. It underwent numerous renovations before being abandoned in the 18th century. It was converted into a prison in the 19th century, and then in the following century, after a mayor restoration, it was made into a Historical Archives. In spite of all these events, the Castle of León still looks like a medieval fortification.

Key words: Castle, Leon, military architecture, restauration, patrimony.
\end{abstract}

Cada monumento es el resultado de su historia, y el Castillo de León es un edificio que atesora una larga biografía llena de vicisitudes de todo tipo. Comienza en la antigüedad formando parte de un campamento militar y su condición va cambiando con el paso del tiempo; además de la real y la castrense, que le es propia por definición, sirvió de cárcel en distintas etapas, fue sede del poder y emblema de la ciudad, hasta llegar a nuestros días como Archivo Histórico. Sus muros han visto importantes hechos históricos, tanto para la ciudad como para España, y por sus dependencias han pasado muchos personajes ilustres, unas veces como protagonistas afortunados y poderosos, otras como simples condena- dos. Sus piedras han recibido la visita de ejércitos de toda clase, romanos y astures, cristianos y musulmanes, franceses y españoles, regulares o sublevados. En unas ocasiones fue símbolo de la monarquía y residencia de gobernantes, en otras sirvió para castigar. Pero también hubo etapas en las que estuvo lastimosamente abandonado, esperando nuevos señores o nuevas funciones. Estas cuestiones hacen de él un monumento que guarda una importante memoria histórica entre sus muros, los cuales han sufrido distintas reformas para adaptarse a las necesidades según iban cambiando. Todo esto dificulta enormemente la realización de un análisis completo de sus múltiples valores. Así, sus avatares están 
recogidos en varios tipos de documentos, aunque no numerosos, desperdigados en archivos diferentes o perdidos. Por otro lado, su estudio admite muchos puntos de vista, desde el puramente histórico hasta el arquitectónico, con la posibilidad de enfoques distintos en cada disciplina. No obstante, al ser un edificio que no puede ser considerado de categoría excelente dentro de la historia de la arquitectura española, no ha merecido todavía análisis específicos de los especialistas. En el presente trabajo nos proponemos hacer una aproximación al edificio por su enorme valor patrimonial, al margen del meramente arquitectónico o artístico, realizando un estudio de carácter general, que permita el conocimiento global de sus significados y siente bases para otros posteriores sobre aspectos más concretos, e incluso interpretaciones nuevas que se puedan hacer a la luz de la documentación que todavía permanece inédita.

\section{EL EDIFICIO}

El castillo se encuentra formando parte del lienzo septentrional de la muralla romana, por lo tanto su origen entronca directamente con el de la ciudad de León y con la Legio VII Gémina. Esta legión, creada en el año $68 \mathrm{~d}$. C. por Galba, gobernador entonces de la Tarraconensis, fundó su campamento en el último cuarto del siglo I en el noroeste de Hispania, escogiendo para ello un lugar cercano a la confluencia de los ríos Bernesga y Torío $^{1}$. El asentamiento tuvo carácter fijo, lo que supuso la construcción de unas estructuras de índole permanente y carácter consistente, que, con su continuidad en el tiempo, dieron origen a la ciudad de León ${ }^{2}$.

\footnotetext{
${ }^{1}$ Sobre la fundación de la ciudad véase, entre otros, A. GARCÍA BELLIDO, Nueve estudios sobre la Legio VII Gemina y su campamento en León, León, 1968.

${ }^{2}$ Las últimas excavaciones realizadas en León han confirmado que en el mismo lugar estuvo asentada antes otra legión, la Legio VI Victrix, fundada en el año
}

Los legionarios hicieron su campamento siguiendo para su confección las conductas habituales en el ejército romano. Cavaron un foso perimetral y levantaron una robusta muralla con pequeños sillares de piedra ${ }^{3}$. Durante la época bajoimperial hubo una etapa de inseguridad y temor ante un posible ataque exterior, por lo que las autoridades decidieron hacer más poderosas las defensas, aumentando la altura y el grosor de las murallas. Al muro primitivo se adosó otro, el que en la actualidad está a la vista ${ }^{4}$, que superaba los cinco me-

41 a. C. por el futuro emperador Augusto, que llegó a la zona leonesa hacia el año15 a. C. posiblemente con motivo de las guerras contra astures y cántabros; las construcciones que hicieron entonces fueron sustituidas por otras más sólidas cuando se estableció la Legio VII; cfr., J. L. AVELLO ÁLVAREZ, «El ejército romano y el origen del urbanismo en la actual provincia de León», Actas del VIII Congreso Nacional de Historia del Arte, Mérida, 1993, p. 941; V. GARCÍA MARCOS Y J. VIDAL ENCINAS, «Asturica Augusta y Castra Legionis VII Geminae en la Asturia Cismontana», en Astures, Oviedo, 1995, pp.113-127. Los datos más recientes sobre el primitivo campamento augusteo se pueden consultar en V. GARCÍA MARCOS, «Novedades acerca de los campamentos romanos de León», Arqueología militar romana en Hispania, Madrid, 2002, p. 167-211; E. CAMPOMANES ALVAREDO Y OTROS, «Ocupaciones militares anteriores a la llegada de la Legio VII Gemina a la ciudad de León», Arqueología militar romana en Hispania, Madrid, 2002, pp 339-347.

${ }^{3}$ V. GARCÍA MARCOS, «Novedades acerca de..., p. 186, recoge los datos más sobresalientes sobre la primitiva muralla. En la actualidad hay muy pocos vestigios de esta construcción, siendo los más interesantes los que se encuentran al lado de la torre del Gallo de la colegiata de San Isidoro.

${ }^{4}$ M. RISCO, Historia de la Ciudad y Corte de León y de sus Reyes, Madrid, 1792, afirmaba que esta muralla había sido levantada en la Edad Media, sobre los cimientos de la romana, idea seguida por parte de la historiografía posterior. Sin embargo, hoy en día se cree que la muralla actual fue levantada en los siglos III y IV, siguiendo la teoría de I. A. RICHMOND, «Five town-walls in Hispania Citerior», The Journal of Roman Studies, XXI, Londres, 1931, pp. 86-100. Véase también, A. BALIL IllanA, «La defensa de Hispania en el Bajo Imperio», Zephyrus, XI, 1960, pp 179-197; C. FERNÁNDEZ OCHOA, y A. MORILlO CERDÁN, «Fortificaciones urbanas de época bajoimperial en Hispania. Una aproximación crítica», PAUAM, no 18-19, 1991; E. 
tros de anchura y los ocho de altura, hasta conformar un gran rectángulo con las esquinas redondeadas ${ }^{5}$. Fue construido en piedra, con aparejo de mampostería hecho en tongadas encofradas, reforzándose en tramos regulares de unos 15 metros de longitud con torres macizas de idéntico aparejo, con planta semicircular peraltada, de un diámetro que mide alrededor de los 8 metros y una proyección cercana a los 6,50 metros. Estos cubos se adelantan a los lienzos para hacer más efectiva su defensa, al tiempo que otorgan una mayor sensación de fortaleza y cumplen una misión constructiva actuando como contrafuertes.

En el perímetro amurallado se abrían cuatro puertas, orientadas según la dirección de los puntos cardinales y dando paso a los dos ejes viarios principales del campamento. Estaban formadas por un efectivo sistema defensivo con torres flanqueando los vanos, que protegían el paso al interior del recinto ${ }^{6 .}$ Nuestro castillo está contiguo a una de las cuatro puertas romanas originales, la conocida en su origen como Porta Decumana y a partir de la Edad Media como Puerta Castillo, la única que subsiste hoy en día, aunque su fisonomía actual se deba al

CAMPOMANES ALVAREDO, «Nuevas perspectivas sobre el recinto amurallado romano de León», Congreso Internacional Los orígenes de la ciudad en el noroeste hispánico, t. II, Lugo, 1996, pp. 1057-1076, V. GARCíA MARCOS, «Novedades acerca de..., p. 186.

${ }^{5}$ Las murallas de León, tanto la romana como la posterior medieval que amplió el espacio de la ciudad, fueron declaradas Monumento Histórico el 3 de junio de 1931, véase, AA VV, Arquitectura monumental en la provincia de León, León, 1993, pp. 50-53; J. RIVERA BLANCO, Catálogo monumental de Castilla y León, Salamanca, 1995, pp. 327-328.

${ }^{6}$ Podemos deducir su forma gracias a los vestigios originales de la puerta oriental, Porta Principalis Sinistra, conocida desde la Edad Media como Puerta Obispo por estar situada entre la catedral y el palacio episcopal, que han salido a la luz en unas recientes excavaciones hechas al lado de la catedral. Veáse, V. GARCíA MARCOS, «Novedades acerca de..., p. 190-192. proyecto llevado a cabo en el siglo XVIII ${ }^{7}$. Creemos, sin ninguna duda, que la primitiva ubicación de la fortaleza estuvo vinculada con ella, de manera que en algún momento se reforzó esta entrada con la construcción a su lado de una fortificación para afianzar la protección de la ciudad en general y del acceso que custodia en particular.

La estructura del castillo de León es singular, muy alejada de las tipologías habituales. Se halla integrada en la antigua muralla y está generada a partir de ella, utilizando parte de sus elementos para configurar una fortaleza que pretende tener un funcionamiento independiente, aunque ensamblado en el sistema defensivo general de la ciudad. Así, el núcleo del castillo se conforma a partir de dos cubos de la muralla y de la torre de base cuadrangular situada hacia el este en línea con ellos, junto con el potente lienzo del originario recinto romano que une estos tres cuerpos. Sobre el paramento macizo de la antigua fortificación campamental, que actúa de alto zócalo, se recreció el edificio. Se subieron las paredes siguiendo exactamente las dimensiones y el contorno de la planta, con el fin de conseguir varias alturas donde distribuir las distintas dependencias necesarias para cumplir la misión de castillo.

En el extremo este, al lado de la puerta septentrional de la ciudad, se encuentra la torre de base ligeramente trapezoidal y aparejo exterior de sillería, que por sus peculiares características desentona en el conjunto. Habría que ponerla en relación con otras parecidas que tuvo la muralla de León, como son la torre de los Ponce y la torre de S. Isidoro, que han sufrido importantes modificaciones con el paso del tiempo, y la que estaba en el extremo suroeste del recinto, hoy desaparecida sin dejar ras-

\footnotetext{
${ }^{7}$ Esta puerta ha sido estudiada por E. MorAis VALLEJO, «Puerta Castillo. Una entrada emblemática para la ciudad de León», De Arte, nº 3, 2004, pp. 143-163.
} 
tro. Es difícil precisar con exactitud el momento de su construcción, ya que la sobriedad de sus elementos, sin ninguna concesión a la ornamentación, y las continuas obras a las que fue sometido el castillo, no han dejado los suficientes vestigios para facilitar su datación.

$\mathrm{Al}$ exterior está construida con buena sillería de piedra, aunque en su interior se utilizó sobre todo cal y canto. Hoy aparece desmochada y con menor altura de la que tuvo en otros tiempos, por lo que desconocemos el coronamiento primitivo, lo cual nos facilitaría la interpretación de su significado en el conjunto de la fortificación. La atraviesa un angosto pasadizo, situado al nivel del paso de ronda que circula por encima de la muralla medieval que tratamos más adelante, cubierto con una bóveda apuntada de sillería, donde se encuentran marcas de canteros de características medievales. Estas dos cuestiones, forma y firmas, más el hecho de que el murallón bajo medieval se superpone a la fábrica de sillares, son elementos determinantes para pensar que es una edificación del inicial período gótico, seguramente hecha sobre una base romana; ${ }^{8}$ hipótesis que sólo se podrá confirmar o desmentir mediante una excavación arqueológica de la zona.

El interior de la torre está en su mayor parte macizado, menos un estrecho y descentrado patio de base rectangular (aproximadamente $3 \times 2,70 \mathrm{~m}$.), con paredes que superan los 12 metros de altura. Su acceso se hace a través de una sencilla portada adintelada de marco de piedra, situada a la altura de lo que fue el adarve de la primitiva muralla romana. Se ha especulado sobre el uso de este espacio, en apariencia inútil por sus características, ya que es

-

\footnotetext{
${ }^{8}$ Algunos autores hablan de su origen romano, por ejemplo J. MATEO MARCOS, Origen, evolución y decadencia del recinto amurallado de León, León, 1981, p. 27.
}

un espacio demasiado pequeño y excesivamente alto para ser funcional. El patio no tiene ventanas y la ventilación proviene de la abertura cenital, también única fuente de luz; tampoco se ven mechinales o cualquier otra huella de construcciones anteriores, tan sólo una simple y desornamentada hornacina enfrentada a la puerta. Por todas estas circunstancias pensamos que sería un hueco de escalera en el que habría una estructura de madera para que los soldados subieran a lo alto de la torre, que tendría misiones de vigilancia o defensa.

Durante la Edad Media se levantó un alto y grueso muro, de forma irregular cercana al óvalo, para rodear la estructura descrita. Su objetivo era diferenciar el castillo, definiendo sus límites, dotándole de personalidad propia dentro del recinto amurallado, y aumentando al mismo tiempo su potencial defensivo. Este paredón de figura sencilla, construido con tapias de encofrado de cal y canto, carece de cualquier aditamento estructural o decorativo, a no ser el primitivo revoco que recubriría los paramentos exteriores, y del que hablaremos después. Las paredes, totalmente verticales, tienen en lo alto un camino de ronda que en su día seguramente estaría protegido por un parapeto almenado.

El muro, debido a su diseño, deja en el centro los elementos que constituyen el núcleo esencial del castillo y crea de esta manera dos patios, uno situado delante de la muralla y otro tras ella, como se puede apreciar en la planta que reconstruye hipotéticamente la forma original (fig. 1); dos estrechos pasadizos atraviesan la muralla por su base para poner en comunicación ambos patios. Con este trazado, el castillo gana territorio fuera de la ciudad, pero también dentro. 


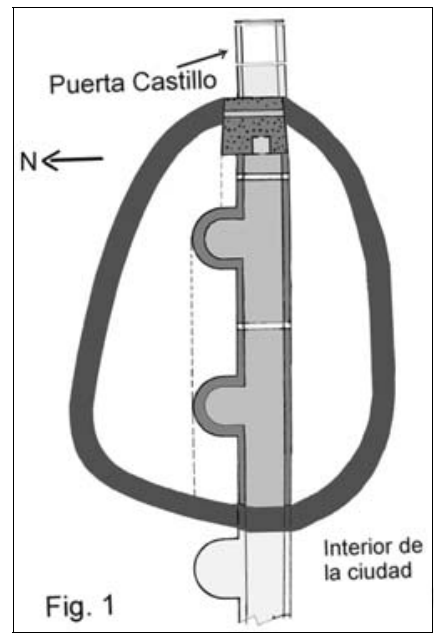

La disposición analizada hace que la barrera defensiva ofrezca protección tanto de los enemigos exteriores como de los interiores, dando la sensación de que hay temor a potenciales revueltas de la población leonesa contra el poder establecido representado por el alcázar. Esta prevención era habitual en los castillos urbanos, pudiéndose por tanto asimilar sus funciones con las propias de las ciudadelas, construidas atendiendo siempre a ambas posibilidades $^{9}$. Los tratados de arquitectura militar de la Edad Moderna no se olvidan de esta cuestión y en algún apartado suelen especular con el latente peligro de la sublevación de los pobladores de la ciudad y, por tanto, de la necesidad de tener prevenida esta eventualidad incluso con fortificaciones interiores ${ }^{10}$. Éstas pueden ser fuertes o ciudadelas, levantados para que guarden las entradas y avenidas forçosa a la plaça, y más comunmente para sujetar sus habitadores, sien-

${ }^{9}$ A. CÁMARA, Fortificación y ciudad en los reinos de Felipe II, Madrid, 1998, p. 60, señala como las connotaciones que tenían los castillos del rey, como éste, hizo que no se utilizara el término de ciudadelas, aunque se tratara de tales en el sentido más teórico del término.

${ }^{10}$ D. GONZÁLEZ DE MEDINA BARBA, Examen de fortificación, Madrid, 1599, p. 116. do vassallos revoltosos o rezien conquistados ${ }^{11}$. En cualquier caso, el muro citado marcaba una frontera, dejando claro tanto a los enemigos como a los súbditos el reducto donde se asentaba el poder real.

Su construcción debió iniciarse entre finales del siglo XIII y principios del siglo XIV, como se está demostrado de manera evidente con argumentos cada vez más sólidos en los últimos años, quedando obsoletas las teorías anteriores que pretendían su filiación a la Edad Moderna. La justificación de esta afirmación se fundamenta en varios criterios. En primer lugar, el tipo de aparejo de cal y canto utilizado es idéntico al empleado para edificar la Cerca medieval de la misma ciudad, la cual se hizo en las fechas indicadas para proteger el crecimiento experimentado por León durante el medievo en la zona conocida como el Burgo $\mathrm{Nuevo}^{12}$; por lo tanto, es fácil deducir que ambos trabajos, a causa de sus similitudes, pertenecen a la misma época, o al menos son muy cercanos en el tiempo. En segundo lugar, nos vamos a fijar en el revoco decorativo mencionado más arriba, que todavía se mantiene en algunas zonas, aunque cada vez en menos. Consiste en una serie de fajas horizontales y paralelas, rellenas con líneas oblicuas dibujadas con la punta de la paleta o de la llana cuando el material estaba todavía fresco. Este motivo, tanto en su diseño como en su materialidad, es igual al que cubría los lienzos de la muralla leonesa a finales de la Edad Media. Por lo tanto, podemos considerar a este sencillo adorno

\footnotetext{
${ }^{11}$ S. FERNÁNDEZ MEDRANO, El arquitecto perfecto en el arte militar, Amberes, 1708, p. 156.

12 Sobre la construcción de esta cerca tratan diversos autores, cfr. E. BENITO RUANO, «Las murallas y cercas...; A. Represa, «Evolución urbana de León en los siglos XI-XIII», León y su Historia, t. I, León, 1969, pp. 243-282; J. A. GuTIÉRREZ GONZÁLEZ, Fortificaciones y feudalismo en el origen y formación del reino leonés, Valladolid, 1995, pp. 239-249; C. Álvarez ÁlvareZ, La ciudad de León en la Baja Edad Media. El espacio urbano, León, 1992, pp.41-63.
} 
medieval de los paramentos como un documento histórico que nos indica una cronología aproximada ${ }^{13}$. Además, hemos de tener en cuenta que si durante todo el medievo, en las referencias documentales que conocemos, se habla siempre del castillo como un edificio con personalidad propia, es lógico pensar que estaría delimitado por algún tipo de cerramiento con la suficiente entidad como para distinguirlo con claridad del resto del recinto amurallado.

Algunos autores han denominado a este muro revellín ${ }^{14}$, pero en realidad no es tal elemento, por diferentes razones. En primer lugar porque únicamente entendemos por revellín una obra exterior, propia de la fortificación moderna, según queda definido en la poliorcética de cualquiera de los tratados de arquitectura militar escritos a partir del siglo XVI. En segundo lugar por su forma de apariencia medieval, muy alejada de los dibujos triangulares y con las caras en talud que reglamenta toda la tratadística renacentista y barroca para garantizar su efectividad. Tampoco por su situación, ya que los revellines se colocan delante de las cortinas de manera independiente, sin contacto con ellas, pues están pensados para ejercer una defensa exterior cubriendo los flancos de los baluartes, que aquí no existen. Nunca tienen una continuidad hacia el interior del recinto, como sucede en este caso, pues carece de sentido en su mi-

${ }^{13}$ J. M. VIDAL ENCINAS Y OTROS, «Un asunto superficial: el revoco decorativo del recinto romanomedieval de León», De Arte, nº 1, León, 2003, p. 17. Este estudio afirma que la muralla leonesa estaba revocada y que en algunos lugares se decoraba con bandas horizontales de unos 20-30 cms. de anchura con las características descritas. Se fija para este elemento la cronología de fines del siglo XIII - XIV. El artículo hace especial mención de esta cuestión en referencia al muro del castillo que estamos tratando.

${ }^{14}$ Así lo hace por ejemplo M. GÓMEZ MORENO, Catálogo monumental de la provincia de León, Madrid, 1925, p. 176, y todos los historiadores posteriores que le remedan. sión específica. Por otro lado, hay que tener en cuenta que su aparejo, su grosor, su altura y su verticalidad son inútiles para resistir la fuerza del fuego artillero moderno, por lo que pensamos que estaría construido antes de las innovaciones diseñadas por los ingenieros renacentistas.

Así pues, por todo lo expuesto hasta aquí, podemos concluir que el muro que hoy vemos se hizo en la Baja Edad Media, en un momento que por ahora no es posible concretar debido a la falta de documentación, con el fin de acotar el espacio del castillo de la ciudad y aumentar su potencial defensivo ${ }^{15}$. No descartamos que antes de éste hubiera otro cierre realizado con las mismas intenciones, pero los datos actuales sólo permiten aventurar hipótesis en ese sentido.

Al núcleo inicial se fueron añadiendo a lo largo de la historia nuevos espacios o elementos estructurales, y modificando otros, hasta llegar a la forma actual, que presenta algunas mutilaciones y cambios sobre la apariencia que tenía en la Edad Moderna, propios de las huellas dejadas por el transcurrir de los siglos, los malos usos y las restauraciones realizadas, unas hechas con más acierto que otras.

Constatamos que en dibujos y fotos antiguas se pueden ver construcciones adosadas a la cara exterior de la muralla romana, aprovechando el saliente de las torres, siendo siempre de altura inferior a la de los muros en los que se apoyaban. Todo esto desapareció en la reforma realizada por E. González Mercadé en el s. XX, por lo que resulta imposible saber en que época fue añadido al núcleo del castillo.

\footnotetext{
${ }^{15}$ Algunos autores lo creen construido en el siglo XVI, pero sin una base documental sólida, véase por ejemplo, J. A. GutiérREZ GONZÁLEZ, ob. cit., p. 239.
} 
Con el paso del tiempo, en momentos en los cuales su interés militar era menor, el recinto del castillo sufrió dos amputaciones en el segmento que mira a la ciudad. La primera tiene que ver con la ubicación en sus inmediaciones del convento de los Franciscanos Descalzos ${ }^{16}$, quienes ocuparon una parte del espacio correspondiente a la primitiva muralla romana y derribaron una sección de la medieval para encastrar allí su iglesia. Los frailes, para ampliar su convento, ocuparon parte de las dependencias castellanas, lo cual tuvo que ocurrir en una época que la fortaleza estuviera sin funciones, o al menos con ellas disminuidas $^{17}$. La segunda quiebra ocurrió a principios del siglo XIX cuando se convirtió en cárcel, como veremos en la segunda parte, y se levantó un nuevo edificio a espaldas de la muralla romana para ubicar dependencias administrativas y hacer el acceso al recinto carcelario (fig. 2).

\section{-}

${ }^{16}$ Dentro de las propiedades de la colegiata de S. Isidoro estaba el antiguo hospital de San Froilán, de fundación medieval, que se extendía desde el palacio abacial que lindaba con el lienzo occidental de la muralla hasta las inmediaciones del castillo. El 25 - X 1596 el cabildo isidoriano acordó ceder por cuatro años el citado hospital a los Franciscanos Descalzos, que querían establecerse en León. El martes de Semana santa de 1601 se lo adjudicaron de forma definitiva, quedando por perpetuos inquilinos y huéspedes del sitio y hospital de San Froilán. Sobre este tema véase, J. PÉREZ LlAMAZARES, Historia de San Isidoro, León, 1927, pp. 201, 270 y 276-278; J. M. QUADRADO, Recuerdos y bellezas de España. Asturias y León, Madrid, 1855, p. 366.

En mayo de 1602 el rey Felipe III aceptó, como patrono que era de la colegiata, la cesión del hospital de San Froilán a los frailes descalzos para que instalaran allí su convento, según se recoge en la correspondiente cédula real, Archivo Histórico Municipal de León (desde aquí AHML), Catálogo de documentos, leg. 21, no 905.

${ }^{17}$ J. M. VillanUeVA LÁzARO, La ciudad de León, de romana a románica, León, 1982, p. 42, afirma que "la ciudad de León escribió al rey Felipe III que por el bien que habían hecho y hacían, y para ensanchar el convento, les habían dado un pedazo del antiguo castillo", pero no cita la fuente documental.
Probablemente esta reforma destruiría la primitiva portada del castillo, de la que no se tienen noticias, por lo que presumimos sencilla y de poco arte.

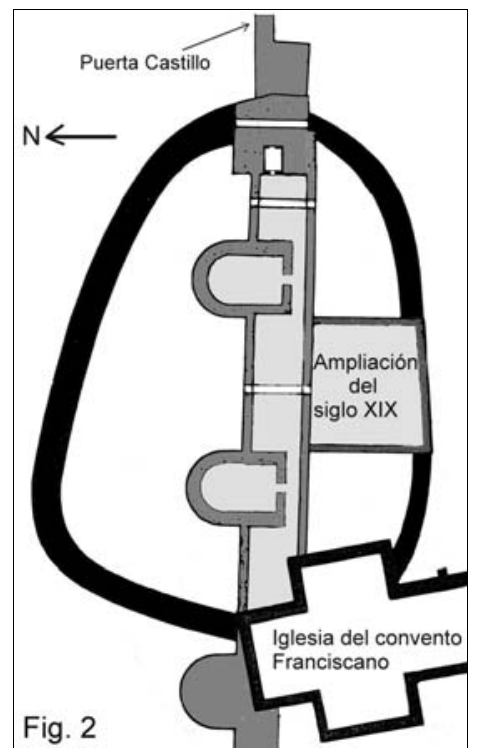

La fábrica de la construcción primitiva es pobre de materiales, apreciándose una curiosa mezcla de aparejos que obedecen a las distintas etapas constructivas, que han quedado marcadas sobre las paredes como heridas cicatrizadas por el tiempo. En la parte inferior, la más antigua y la menos retocada porque es el fundamento sobre el que se alza la edificación, predomina la fábrica romana con el típico trabajo denominado opus incertum. Conforme va ascendiendo el edificio aparecen cantos rodados, sillarejos y algunos sillares aprovechados de edificaciones antiguas, cuya obra se correspondería con los reparos realizados en distintas etapas del medievo y la Edad Moderna. Por último, la transformación decimonónica que convirtió el edificio en cárcel, se utilizó el ladrillo, abundante sobe todo en las zonas superiores, formando verdugadas que se yuxtaponen a los otros aparejos. Tal amalgama de materiales confiere al edificio una apariencia desordenada y tos- 
ca, por lo que suponemos que todos los paramentos exteriores estarían revocados, con diferentes técnicas según cada época, ocultando las deficiencias y dando uniformidad al conjunto.

En cuanto a la ampliación del siglo XIX, que dejó al edificio con la configuración actual, se conforma en planta como un trapecio adosado a la parte trasera de la muralla, situado en simétrica correspondencia con el tramo entre los cubos. Para ubicarlo se derribó, sin ningún miramiento, una parte del murallón que definía la fortaleza antigua. El alzado es muy sencillo, desornamentado y de escasa personalidad. La fachada, encajada entre la cerca y enrasada con ella, toma una dirección oblicua para seguir su línea, lo que le da su forma trapezoidal. Es de tres alturas, abriéndose en la inferior la portada, a la que se accede por una escalera doble con pretil abalaustrado para salvar el nivel desde la calle; los sillares de las esquinas y del marco del vano son el único alarde decorativo presente en una concepción racionalista y funcional. En el segundo piso se disponen tres sencillas ventanas adinteladas, con un balcón corrido delante de ellas. La última altura tiene forma triangular con un único vano en su centro. Se remata con un reloj acompañado de una campana superior.

\section{HISTORIA CONSTRUCTIVA Y FUNCIO- NAL DEL CASTILLO.}

Por los datos que disponemos en la actualidad no podemos saber si en la antigüedad los romanos levantaron algún tipo de fuerte en este lugar, con la intención de reforzar la defensa de la puerta Decumana, pues no se han encontrado restos fehacientes que lo demuestren, ni documentación que lo certifique de manera irrefutable. Tampoco sabremos si su origen es romano hasta que no se realice una exhaustiva in- vestigación arqueológica de los restos del subsuelo $^{18}$. No obstante, la posibilidad de un fuerte romano, ampliado posteriormente en la Edad Media, no debe descartarse de antemano, pues, aunque todas las puertas romanas tenían un sistema de torres para custodiar mejor las entradas, es probable que ésta necesitara un particular refuerzo y mayor vigilancia. En este sentido apuntamos que está orientado hacia el norte y el noroeste, donde vivían los astures menos romanizados que podrían causar más problemas al campamento, sin olvidar que uno de los motivos del asentamiento legionario fue la importancia de los recursos mineros, especialmente auríferos, del noroeste peninsular $^{19}$. Así mismo, destacamos el hecho de que por este lugar entraba el principal acueducto que recogía el agua de una importante zona acuífera cercana al campamento legionario ${ }^{20}$. A esto hay que añadir el hecho de que a partir del arca principal, situada a espaldas de la puerta, se distribuía el agua por el interior del recinto fortificado gracias a una estudiada red de cañerías $^{21}$, lo que parece un buen argumento para reforzar en particular esta entrada a diferencia de las demás.

\footnotetext{
${ }^{18}$ Las excavaciones realizadas en esta zona por C. FERNÁNDEZ ALLER, cuyos resultados se recogen en su Tesis Doctoral Legio VII Gemina. Aportaciones a la historia romana de León, Salamanca, 1972, p. 243, no llegaron a encontrar el fundamento romano primitivo de esta zona, lo que hubiera desvelado la existencia o no de una fortaleza anterior a la medieval.

${ }^{19}$ V. GARCÍA MARCOS, “Novedades acerca ..., p. 182.

${ }^{20}$ Sobre el abastecimiento de aguas en la época romana, véase, M. GONZÁLEZ FLóREZ, «Historia del abastecimiento de aguas a la ciudad de León (I)», Tierras de León, nº 41, León, 1980, pp. 17-20; M. SANTANDER, «Notas sobre el acueducto romano de León», $B S A A$, Valladolid, 1970, p. 466.

${ }^{21}$ Uno de los ramales principales apareció a espaldas del castillo a raíz de unas excavaciones realizadas a principios del año 1985, según se recoge en J. M. VIDAL ENCINAS, «Arqueología urbana en León: precedentes y aportaciones recientes», Archivos Leoneses, t. XL, no 79-80, 1986, pp. 370-372.
} 
La ubicación de las fortalezas tiene habitualmente una estrecha relación con la topografía, siendo muchas veces determinante para su erección la situación sobre el territorio y el dominio que puede ejercer sobre el espacio circundante. Aquí podemos constatar que está situada en la parte más alta de todo el recinto amurallado, ofreciendo otra buena razón para su localización.

Pudiera ser que el castillo inicial se hiciera en las primeras etapas de la reconquista $^{22}$, de hecho Manuel Risco cuenta que en los primeros veinte años del siglo XI se reedificaron e hicieron varias edificaciones nuevas, señalando entre ellas un palacio suntuoso en un solar, que tenía dos torres de la muralla antigua, obra del conde Munio Fernández y su mujer doña Elvira ${ }^{23}$. Por su descripción, haciendo mención expresa a dos cubos de la muralla, es por lo que creemos que, casi con total seguridad, se estaba refiriendo al castillo en cuestión ${ }^{24}$. No es una información determinante, ni tampoco aclara si las obras emprendidas por el conde eran una reconstrucción, una ampliación o cualquier otro tipo de intervención destinada a mejorar la habitabilidad de un palacio anterior, o por el contrario, era la primera vez que se adaptaban estas partes de la muralla para hacer la residencia condal, en cuyo caso sería el origen del castillo. Al respecto no debemos olvidar que este tipo de fortalezas eran un símbolo de la autoridad efectiva e institucionalizada del monarca ${ }^{25}$, por lo que preocupaba su mantenimiento en las mejores

\section{-}

${ }^{22}$ L. MATEO MARCOS, ob. cit., p. 20.

${ }^{23}$ M. RisCO, op. cit., p. 18.

${ }^{24}$ Recordamos que al hablar de las distintas edificaciones del castillo ya hicimos mención a estas estructuras adosadas.

${ }^{25}$ C. AYALA MARTínEZ, «Los castillos leoneses, núcleos de jerarquización política y articulación señorial (s. XIII-XIV)», en Castillos y fortalezas del reino de León, Madrid, 1989, p. 34. condiciones posibles, siendo las reformas constantes.

Tuviera el castillo un antecedente romano, reformado y ampliado más tarde, o fuera levantado por primera vez en el medievo, lo único cierto es que a la citada puerta ya se la nombra en la documentación desde la alta Edad Media como Puerta Castillo, señalando de esta manera su contigüidad con el edificio militar ${ }^{26}$. Además, el hecho de que se llamara también a esta entrada desde principios del siglo $\mathrm{X}$ como Puerta del Conde ${ }^{27}$, es un indicio bastante elocuente de que en esta época ya estaba a su lado la edificación donde tenía su sede el conde encargado de la defensa de la ciudad, el tenente del castillo ${ }^{28}$, algo así como un delegado del poder regio, más que un mero castellano, por lo tanto estrechamente vinculado a la administración territorial del reino ${ }^{29}$.

La muralla, construida en su origen por los romanos, se convirtió durante la Edad Media en el factor definidor de la $\operatorname{ciudad}^{30}$, no sólo porque representa entonces la seguridad para los ciudadanos, frente al peligro del campo abierto ${ }^{31}$, sino, y sobre todo, porque era la línea divisoria que de-

${ }^{26}$ Véase E. MORAIS VALLEJO, «Puerta Castillo...., pp. 143-150.

${ }^{27}$ El primer documento que habla de esta puerta como Porta de Condis se remonta al año 916, según C. EstePa DíeZ, Estructura social de la ciudad de León. Siglos XI-XIII, León, 1977, p. 119, nota 63.

${ }^{28}$ Las referencias a la tenencia de la fortaleza de León son numerosas en la documentación. Una serie interesante de documentos fechados entre 1479 y 1681 se pueden consultar en AGS, Contaduría del Sueldo, legs. 374, 376, 380.

${ }^{29}$ C. EstePa DíEZ, ob. cit., p. 441; C. Álvarez ÁLVAREZ, La ciudad de León en la baja Edad Media. El espacio urbano, León, 1992, p. 131.

${ }^{30}$ A. ISAC, «Ciudad cerrada y ciudad abierta. La muralla en la historia de la ciudad", La ciudad y sus murallas, Granada, 1996, p. 67.

${ }^{31}$ J. VALDEÓN BARUQUE, «Reflexiones sobre las murallas urbanas de la Castilla Medieval», en La ciudad y las murallas, Madrid, 1991, p. 
limitaba un espacio jurídico, administrativo, comercial y fiscal distinto, donde los ciudadanos gozaban de unos derechos que no tenían los que vivían en el mundo ru$\mathrm{ral}^{32}$; de esta manera, la muralla materializaba la idea de un recinto acotado, donde sus límites eran algo consustancial al concepto de ciudad. Pronto pasó a ser uno de los componentes más emblemáticos de León, destacándose en medio de ella la fuerza simbólica del castillo, ubicado al lado de una de las puertas principales de la ciudad, con todo el significado político, comercial y recaudatorio que ello significaba en aquellas fechas.

En la época medieval, larga y belicosa, las fortificaciones tenían valor como elemento disuasorio para prevenir ataques. Así, los foráneos siempre vieron a la muralla y a la fortaleza de León como los grandes obstáculos para la conquista de la ciudad, siendo objetivo militar de primer orden. Los primeros daños considerables vinieron con los musulmanes en el año 846, cuando el futuro emir Muhammad I las sometió a una acción devastadora, pero no a su demolición, ya que, como relata el cronista Ibn Idari, renunció a su destrucción por su gran espesor ${ }^{33}$. Más tarde el recinto amurallado favoreció las necesidades repobladoras de los cristianos, que ocuparon la ciudad hacia 856 a las órdenes de Ordoño $\mathrm{I}^{34}$, siendo convertida pronto en residencia preferente de la corte ${ }^{35}$. Las razias musul-

\footnotetext{
${ }^{32}$ Alfonso X en la Partida VII, tit. XXXIII, ley VI, ya había definido a la ciudad como ...todo aquel lugar que es cercado de los muros, con los arrabales et los edificios que se tienen con ellos.

${ }^{33}$ E. BENITO RUANO, «Las murallas y cercas de la ciudad de León durante la Edad Media», en León medieval. Doce Estudios, León, 1978, p. 29, recoge la traducción francesa de FAGNAN, así como otras versiones musulmanas recuperadas por SÁNCHEZALBORNOZ sobre los mismos hechos.

${ }^{34}$ C. ESTEPA DíEZ, ob. cit.,p.115, estima que la ciudad no estaría desierta, pero si con escasa población.

${ }^{35}$ J. VALDEÓN BARUQUE, ob. cit., p. 78.
}

manas acaecidas entre finales del siglo $\mathrm{X} y$ principios del siguiente, primero protagonizadas por Almanzor y más tarde por Abd al-Malik, deterioraron considerablemente el sistema defensivo. No obstante, estos ataques no supusieron tampoco su destrucción total, sino que la acción de las tropas islámicas tuvo como fin tan sólo aportillar los muros para dejarlos fuera de servicio ${ }^{36}$.

Durante el reinado de Alfonso $\mathrm{V}$ (999-1028) se acometió la primera gran restauración de la que se tiene noticia, que, según cuentan las crónicas de la época, se hizo básicamente utilizando sólo tierra y madera $^{37}$. Posteriormente los arreglos fueron frecuentes para mantener en buen estado la defensa de la ciudad. Sobre las reformas realizadas en los siglos XII y XIII quedan vestigios documentales, como son los dos sillares con sendas inscripciones que se pueden observar en la cara exterior de Puerta Castillo ${ }^{38}$. En el siglo XIII doña Berenguela inició la reparación de las torres donde se incluiría también la del castillo, pues la documentación de la época utilizaba el término de torres asociado al de castillo-, que se continuaría en sucesivos reinados del siglo siguiente ${ }^{39}$. A finales del siglo $\mathrm{XV}$, ante los graves daños que presentaban algunos cubos del recinto debido a los avatares de la historia, los Reyes Católicos autorizaron al concejo de León una sisa de

-

${ }^{36}$ M. RISCO, ob. cit., p. 18.

${ }^{37}$ M. RISCO, op. cit., p. 19. C. ESTEPA DíEZ, ob. cit.,p. 142, duda de la autoría de Alfonso V y apunta la posibilidad de que sea obra de Fernando I.

${ }^{38}$ Estas inscripciones han sido analizadas por L. MARTínEZ ÁNGEL, «Puerta Castillo de León. Novedades epigráficas medievales», Tierras de León, $\mathrm{n}^{\mathbf{o}}$ 114, León, 2002, pp. 95-103.

${ }^{39}$ Según la crónica del Tudense, cfr. E. BENITO RUANO, «Las murallas y cercas..., p. 31; M. RISCO, op. cit., p. 70; también, M. GÓMEZ MORENO, op. cit., p. 176. 
60.000 maravedíes para llevar a cabo los reparos considerados más urgentes ${ }^{40}$.

Felipe II, en los últimos años de su reinado, emprendió una gran intervención en el castillo y la muralla ${ }^{41}$, según nos cuenta el cronista Prudencio de Sandoval al narrar la historia de León ${ }^{42}$. En ese momento parece que se atendió al tratadista Cristóbal de Rojas, quien por aquellas fechas defendía con vehemencia el mantenimiento de los amurallamientos antiguos, reformándolos antes que tirándolos para hacer otros nuevos, entre otras cuestiones por el ahorro que suponía en una época no especialmente boyante $^{43}$. El rey firmó una cédula en julio de 1593, en la que expresaba su voluntad de que se reedificasen y alzasen las torres de la fortaleza de la ciudad de León en el menor plazo de tiempo posible ${ }^{44}$. Fue, sin ninguna duda, la intervención más ambiciosa que se hizo antes llegar a la época contemporánea.

${ }^{40}$ E. BENITO RUANO, “Las murallas y cercas..., p. 39.

${ }^{41}$ La documentación de la obra se encuentra en el Archivo de la Catedral de León (desde ahora ACL), Fondo General, doc. 11.164, La fortaleça de Leon. Año de 1593.

${ }^{42}$ P. SANDOVAL, Historia de los Reyes de Castilla y de León, Pamplona, 1634, en el folio 129 v., dice que [en la era 1160, año 1122] ..estavan reveldes y fortifiçados algunos de la parcialidad de la Reyna doña Urraca, y aun dizen historias que la mesma doña Urraca, en sus torres de León, que son unos castillos fuertes para aquellos tiempos, que oy día permanecen reparados por mandado del rey don Felipe Segundo de gloriosa memoria... (el subrayado es nuestro).

${ }^{43}$ Muchas vezes se fortifica o repara una ciudad o castillo viejo ... acomodando lo mas que se pudiere la muralla que huviere vieja... por ahorrar la costa, lo qual tendrá siempre por blanco el tal ingeniero, C. DE ROJAS, Teórica y práctica de la fortificación, conforme las medidas y defensas destos tiempos, Madrid, 1598, fol. 77.

44 ...dixeron que la voluntad del Rey nuestro sr. hera que la dicha fortaleça torres y castillo desta dicha ciudad de que es tal alcayde y de el dicho señor Juan Ruiz de Velasco, que se reedificasen y alçasen conforme a las trazas y condiçiones, ACL, doc. 11.164, fol. 2.
Para ejecutar la reforma se contaba con el correspondiente proyecto que había hecho, por encargo real, el maestro de cantería Pedro de Mazuecos, titulado en la documentación como arquitecto de su majestad. En el proceso de construcción quedaban implicadas varias personas con funciones concretas dentro de las diferentes esferas involucradas en la empresa. En primer lugar Pedro de Mazuecos, autor intelectual de las trazas y condiciones de la obra, que actuaría además con el cargo de veedor de la fábrica. El maestro de obras Leonardo de la Cajiga, originario de Trasmiera, elegido tras ganar el oportuno contrato en concurso público, según veremos a continuación, encargado de materializar el proyecto ejerciendo la dirección de la obra. Juan Ruiz de Velasco, personaje de la cámara de su majestad, quien, al ser el alcaide de la fortaleza tenía un papel destacado y la responsabilidad de llevar los trabajos a buen fin ${ }^{45}$. Vitorio de Villafañe, teniente de alcaide del castillo, que habría de asistir con el título de superintendente, encargándose por tanto de misiones tan importantes como la de vigilar al maestro para comprobar en todo momento que cumplía con la traza y las condiciones pactadas, tanto en tiempo como en forma, comunicando a las autoridades pertinentes los incumplimientos o las posibles negligencias; además también tenía ciertas misiones económicas, siendo, por ejemplo, el encargado de hacer todos los pagos surgidos por los trabajos, que debía atender de la manera más puntual

\footnotetext{
${ }^{45}$ Juan Ruiz de Velasco fue regidor de León hasta agosto de 1600, fecha en la que renunció a sus cargos, según se recoge en AHML, Oficios de Ayuntamiento, caja 133, no 2, s/f.: ...Juan Ruiz de Velasco, cavallero de la Orden de Señor Santiago, secretario de V. M. y de la reyna $N^{\underline{a}} S^{\underline{a}}$ y alcayde de las torres y castillo de la ciudad de Leon y regidor della, vezino desta villa de Madrid, digo que por causas que a ello me mueven renuncio al dicho oficio de regidor en manos de V. M. y en favor de don Juan Velasco y Cerezeda mi sobrino que es persona abil y suficiente y en quien concurren las calidades necesarias.
} 
posible. Iñigo Zumel de Saravia, en su papel de delegado real, por ser corregidor de la ciudad de León y sus tierras ${ }^{46}$, debía asistir a todas las diligencias necesarias para el buen resultado de la empresa. El licenciado Castro de Mendoza, teniente de corregidor, personaje decisivo, pues, al llevar la contabilidad oficial, era el encargado de presentar la justificación de todos los gastos e ingresos generados en el proceso ${ }^{47}$.

La obra, según se acostumbraba en la época, fue sacada a subasta pública, con la intención de que se hiciera a destajo para acortar al máximo posible los plazos de ejecución. Se publicaron varios edictos en la capital y también en otros lugares para que las trazas y condiciones fueran conocidas por el mayor número posible de maestros de obra, de manera que pudieran ser más ajustadas las ofertas. La fecha para hacer posturas y bajas quedó fijada para septiembre del año 1593. Llegado el momento de hacer las primeras licitaciones, Leonardo de la Caxiga, maestro de cantería y vecino de León ${ }^{48}$, se comprometió a realizar el proyecto por la cantidad de 5.500 ducados. Posteriormente, el remate se fijó para el 12 de septiembre del mismo año; ese día el pregonero público, Alonso Hernández, anunció repetidas veces la cantidad ofrecida en espera de que hubiera mejor postor. Después, en la plaza de Santa María de Regla, se procedió al acto propio de la subasta a la

\footnotetext{
${ }^{46}$ Iñigo Zumel no llegaría a ver concluido el proyecto, pues en 1599 ya no era corregidor de León, habiéndose nombrado para esa fecha a Antonio de Maldonado, según se recoge en Archivo General de Simancas (desde aquí AGS), Contaduría Mayor de Cuentas III, leg. $1.704, \mathrm{n}^{-}$46, s/f.

47 Todos ellos nombrados en la documentación, véase, ACL, Fondo General, doc. 11.164, f. 2r-4r.

${ }^{48}$ El trasmerano Leonardo de la Cajiga trabajó a finales del s. XVI como aparejador de Juan del Ribero Rada durante varios años, haciendo más tarde diversas obras en León como maestro de cantería, véase, J. RIVERA BLANCO, Arquitectura de la segunda mitad del siglo XVI en León, León, 1982, pp. 49, 111, 152-155.
}

baja, para lo cual se utilizó el tradicional sistema de la vela encendida. Mientras estuvo viva la mecha no apareció nadie que rebajara la cantidad inicial, por lo que se adjudicó la obra a Leonardo de la Caxiga por la citada cantidad, firmándose el documento ante el escribano público del número de la ciudad, Antonio de Zafra, recogido en el correspondiente protocolo notarial ${ }^{49}$.

Poco tiempo después de iniciados los trabajos surgieron los primeros problemas. El maestro de la obra, en sendas cedulas que fueron firmadas también por Pedro de Mazuecos y Vitorio de Villafañe, declara que está obligado a hacer el cuarto nuevo del castillo, situado entre las torres denominadas del conde Fernán González y de los Alcaides $^{50}$, según unos supuestos recogidos en el proyecto que pronto se demostraron erróneos. Así, al empezar a trabajar en los cimientos se descubrió su fragilidad, por lo que era necesario hacer una consolidación no prevista en las condiciones, con el aumento de gasto que ello suponía. Pedro de Mazuecos visitó la obra y concertó con Leonardo de la Cajiga una serie de mejoras para evitar la ruina del edificio, consistentes sobre todo en abrir nuevas zanjas y macizar convenientemente la obra subterránea. Las novedades fueron tasadas en 120 ducados, que se debían abonar en las dos primeras pagas de la obra principal ${ }^{51}$. Pero ahí no acabaron los problemas. Mazuecos hubo de volver en julio de 1596 para comprobar nuevas cuestiones no recogidas en el proyecto inicial y consideradas indispensables para la correcta ejecución de los trabajos. Una vez realizada la visita, el arquitecto emitió un informe en el que se detallaban

\footnotetext{
${ }^{49}$ Los detalles del documento se pueden consultar en, ACL, Fondo General, doc. 11.164, f. 6r-7v.

${ }^{50}$ Con estos nombres debían conocerse los dos cubos que formaban parte del castillo en esa época, como ya vimos al describirlo.

${ }^{51}$ AGS, Contaduría Mayor de Cuentas III, leg. 1.704, no 46, s/f.
} 
las mejoras consideradas indispensables, que fueron tasadas en 400 ducados $^{52}$.

A parte del maestro principal de la obra, también colaboraron otros arquitectos contratados para realizar trabajos específicos. Una de las intervenciones previstas era hacer de nuevo las oficinas del castillo. En 1597 Alonso Enríquez Cornejo, a la sazón corregidor de León, hizo las diligencias pertinentes para proceder al remate de las citadas dependencias. Se organizó la consabida subasta para recibir posturas de diferentes profesionales, estableciéndose el coste de los trabajos en 2.500 ducados. Varios maestros hicieron ofertas a la baja, como Alonso de la Grela, Pedro de la Lastra ${ }^{53}$ o Pedro de Llánez ${ }^{54}$, rebajando considerablemente la cantidad inicial. El último fue quien se hizo con el contrato por tan sólo 1.700 ducados $^{55}$, es decir, 800 menos de los

\footnotetext{
52 Paresçe que ay dos paredones que por la parte de dentro zierran las dos torres del dicho castillo las quales cuando se hizieron las condiçiones y se remato la dicha obra ... no se pudo hechar de ver bien el fundamento y grueso dellas ... $y$ agora a de tener el de la parte de la prision siete pies de grueso y el otro seis pies y an de subir con este grueso hasta resçivir los arcos demas de que los dichos arcos se an de quitar y subir con el mismo grueso que arriva declara dejando hechas todas sus puertas con sus xanbas y dinteles como para el efecto es menester y en el quarto de entre las dos torres y alcaide conbiene por çiertos defectos que an paresçido en la torre del conde se pase y prosiga en tejado hasta topar en el homenaje de la dicha torre dejando hecha una buarda con su puerta que mire a la çiudad para salir y andar la buelta por el omenaje. AGS, Contaduría Mayor de Cuentas III, leg. $1.704, \mathrm{n}^{-}$46, s/f.

${ }^{53}$ Pedro de la Lastra sería uno de los miembros de la conocida familia de los Lastra, varios de los cuales trabajaron en las más importantes obras de la época en León y su provincia. Véase, E. MORAIS VALleJO, Aportación al barroco en la provincia de León. Arquitectura religiosa, León, 2000, p. 68-69.

${ }^{54}$ Pedro de Llánez maestro arquitecto trasmerano, que se inició en el oficio con Juan del Ribero Rada, estuvo activo en León en los años finales del siglo XVI y el primer tercio del siglo siguiente. Véase, E. MORAIS VALLEJO, Aportación al barroco..., p. 70.

55 ...y no huvo quien quisiese haçer otra ninguna baja por lo qual fue rematada dicha obra en el dicho Pedro de Llanez de ultimo y final remate, AGS, Contaduría Mayor de Cuentas III, leg. 1.704, no 46 , s/f.
}

fijados en las condiciones, lo que supone un considerable descuento del $32 \%$ sobre la primera estimación.

Una vez decidida la obra, hecho el proyecto y adjudicada su realización a maestros competentes, había que solucionar la financiación. La legislación tradicional consideraba que los castillos y murallas que resguardaban una ciudad eran propiedad de la corona, aunque su construcción y conservación debía correr a cargo del concejo, porque, en principio, son para la protección de sus ciudadanos. Por la misma razón, cualquier obra, reforma o intervención debía ser autorizada por el rey, aunque la iniciativa para su mejora fuera del municipio y los gastos corriesen de su cuenta. Ahora bien, algunas veces ocurre que los reyes hacen ciertos encargos específicos, siendo entonces lógica la colaboración de la monarquía para sufragar el coste de su construcción o reparación ${ }^{56}$. Ante las frecuentes quejas de los municipios, -que suelen protestar por las insuficiencias de sus recursos y las enormes cantidades de dinero que están obligados a desembolsar para el mantenimiento de las defensas en buen estado, y más cuando las ciudades tienen murallas de gran envergadura como la leonesa-, la monarquía no dudaba entonces en autorizar impuestos extraordinarios para el efecto, como sucedió en León en varias ocasiones ${ }^{57}$.

${ }^{56}$ I. GONZÁLEZ GALLEGO, «Las murallas y los puentes de León en el siglo XIV», en León y su historia, t. IV, León, 1977, pp. 365-411.

${ }^{57}$ Así, por ejemplo, en 1310 se destinaron a las obras de la muralla el impuesto que se percibía sobre las mercancías que entraban a la ciudad, y en 1324 las rentas de las meajas, de los carrales del vino y de los muros. Durante el reinado de Pedro I se hicieron varias derramas para la labra de los muros e adarves $e$ torres, caramanchones, e alimpiando e mondado las cavas; más tarde se aplicó a las obras el dinero de un tributo peculiar, "la alcabalina", cfr. J. VALDEÓN BARUQUE, ob. cit.,p. 82. 
En tiempos de paz era normal que la onerosa conservación de la fortificación se abandonara, pues, no existiendo peligros inminentes, el municipio se ahorraba unos buenos dineros. Cuando no había peligro de guerra su principal función era la de controlar los portazgos, para lo cual era suficiente cualquier tipo de cercamiento, aunque no tuviera una verdadera efectividad militar. No obstante, en determinadas circunstancias, los reyes apremiaban a los concejos a su reparación y puesta a punto ${ }^{58}$, como es el caso que ahora nos ocupa; queda meridianamente claro en las palabras del rey a Vitorio de Villafañe:

...theniente de mi alcayde de las torres de la çiudad de Leon, ya saveis que yo e mandado hedificar e reparar las dichas torres y se a rematado la obra que en ellas se ha de haçer en Leonardo de la Cajiga en çinco mil y quinientos ducados, e por que a nuestro serviçio conviene que os cargueis de la dicha obra $y$ del dinero que para ello yo he mandado y mandare probeer y librar para haçer a sus tiempos las pagas al dicho maestro con ynterbençion del nuestro corregidor ${ }^{59}$.

El monarca estableció varios recursos distintos para pagar las obras. El primero de ellos tiene que ver con la venta de favores reales. En aquella época era habitual que los cargos municipales se comprasen, siguiendo una tradición medieval que se acentuó en el reinado de Felipe II; unos lo hacían por vanidad o afecto a su lugar de origen, sin embargo otros buscaban los pingües beneficios que podían obtener de las extensas atribuciones que tenían los municipios. Quien quisiera tener una dignidad debía desembolsar una buena cantidad de dinero, contribuyendo de este modo a financiar los enormes gastos de la monar-

\footnotetext{
${ }^{58}$ I. GONZÁLEZ GALLEGO, ob. cit., pp. 365-411.

${ }^{59}$ AGS, Contaduría Mayor de Cuentas III, leg. 1.704, $\mathrm{n}^{\mathrm{o}} 46, \mathrm{~s} / \mathrm{f}$.
}

quía $^{60}$. Pues bien, los 2.550 ducados que Juan Ruiz de Velasco estaba obligado a pagar al monarca por la concesión del regimiento de la ciudad de León, servirían para anticipar la primera paga del maestro y para comprar los materiales iniciales de la obra $^{61}$.

Gracias a las cuentas presentadas por los Contadores de la Razón de la Hacienda conocemos otras vías de financiación. En una cédula fechada en Madrid en enero de 1594, se manda al licenciado Chaves, juez de residencia en León, que los 74.620 maravedíes que había aplicado a la cámara de su majestad de las condenaciones que hizo en el desempeño de su cargo, se los entregase a Vitorio de Villafañe, quien los debía invertir en la obra ${ }^{62}$.

Otra cédula, fechada en el Pardo a cinco de noviembre de 1594, ordenaba al contador Juan Vello de Acuña, quien llevaba los libros de la contaduría mayor de la Orden de Santiago, que diese a Antonio Boto, su guarda de joyas, cierta cantidad de dinero, de donde saldría lo necesario para abordar ciertos pagos de la obra de las torres de León ${ }^{63}$.

60 A. Domínguez ORTIZ, El Antiguo Régimen: Los Reyes Católicos y los Austrias, Madrid, 1983, pp 197-198.

61 ...siendo servido de mandar consignar para la paga dellos los dos mil y quinientos çinquenta ducados que estais obligado a pagarme por la merçed que hos hyze de un regimiento de la dicha çiudad, AG S, Contaduría Mayor de

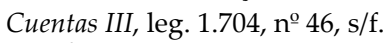

62 ...los diese y entregasen a Vitorio de Villafañe theniente de alcayde de las torres y castillo de Leon para que los gastase en la obra de los dichos castillo y torres que se a mandado comforme a ciertas trazas concertadas con Leonardo de la Cajiga, AGS, Contaduría Mayor de Cuentas III, leg. $1.704, \mathrm{n}^{\mathrm{o}} 46, \mathrm{~s} / \mathrm{f}$.

63 ...Su magestad ...mando al contador Juan Vello de Acuña a cuyo cargo estuvo el exercicio de los libros de la contaduria mayor de la horden de Santiago que de los 1.367.954 que estavan en su poder de los que cobro de los derechos de 37 al procurador que tocan a la dicha contaduria mayor de los arrendamientos de las yervas de las dehesas de la mesa maestral de la dicha horden de Santiago que por no 
Gracias a toda esta financiación y a la aportación municipal, se pudo terminar la reforma del edificio, de manera que al llegar la Edad Moderna el castillo era un referente para la ciudad, habiéndose convertido en seña del poder real, pero también, aunque en estrecha relación con este significado, en cárcel de nobles. En la documentación consultada hemos visto como existe una mención expresa de su función carcelaria a lo largo de los siglos, lo que no es de extrañar porque era frecuente localizar la prisión al lado del recinto amurallado, procurando aprovechar la solidez constructiva de las torres y las puertas para afianzar su seguridad $^{64}$. Desde la Edad Media se tiene constancia de la utilización del castillo leonés como cárcel de nobles ${ }^{65}$. El rey Ordoño II encerró entre sus muros a varios condes castellanos y Ramiro II hizo lo mismo con su hermano Alfonso IV; a ellos les acompaña una larga lista de nobles e ilustres hombres $^{66}$. En la Edad Moderna continuó utili-

aver contador mayor pertenescen a su magestad diese y entregase a Antonio Boto su guarda joyas 1.180.454 para que tomase dellos 238.505 que por mandado de su magestad por esto para cumplimiento de la quarta parte y primera paga de los 5.500 ducados en que se remato la obra de las torres de Leon que es alcayde Juan Ruyz de Velasco y la resta la diese y entregase al dicho Vitorio de Villafañe theniente del dicho Juan Ruiz de Velasco en las dichas torres para que hiziese la segunda paga al maestro Leonardo de la Caxiga ... y por la misma orden que se hizo la primera paga que se continue y de los 187.500 restantes hizo su magestad merced al dicho contador Juan Vello y de la dicha cuenta se mando tomarse razon en los libros de la contaduria mayor de la dicha horden = y aqui se cargan al dicho Vitorio de Villafañe los dichos 1.180.454 para que de quenta dellos, AGS, Contaduría Mayor de Cuentas III, leg. 1.704, nº 46, $\mathrm{s} / \mathrm{f}$.

${ }^{64}$ J. VALDEÓN BARUQUE, ob. cit., p. 84.

${ }^{65}$ En León había otra cárcel, la pública, destinada a todos aquellos presos que no tuvieran sangre noble, ubicada en la zona sur de la muralla y próxima a la denominada Puerta de Arco, hasta que fue trasladada a los antiguos Palacios Reales. Se pueden consultar estos datos en varios documentos municipales, por ejemplo, AHML, caja 17, no 519, s/f.

${ }^{66}$ Cfr. M. BRAVO GUARIDA, Rincones leoneses, León, 1979, pp 126-129. zándose como penal, además de cumplir su misión militar. Ya vimos como en la reforma propiciada por Felipe II se hablaba de una parte del castillo como prisión, y otra como residencia del alcaide ${ }^{67}$. Debía considerarse segura y adecuada para los mayores castigos, pues hasta él enviaron a importantes traidores a la monarquía.

En el reinado de Felipe III se hicieron nuevos trabajos de acondicionamiento. El 21 de mayo de 1607 el monarca firmó en Buitrago una cédula real en la que se disponía la reparación de las torres y castillo de la ciudad de León. Establecía que la cantidad necesaria para pagar las obras, que alcanzaba la cifra de 1.000 ducados, se sacara del dinero que le tocase pagar a León y su provincia del servicio de los millones del año que el reino concedió a su majestad, así como de recargos anteriores. El capital se debía entregar al depositario general de la ciudad, para que, con intervención del corregidor y del teniente de alcaide, Gaspar Celis Cabeza de Baca, se llevaran a buen término las obras y reparos del edificio ${ }^{68}$.

Cuando estuvieron realizadas las labores de reforma, el rey envió una carta al teniente de alcaide, fechada en Madrid el 8 de abril de 1620, informándole de que el licenciado Isidro Castro de Mendoza estaba dando cuenta en la Contaduría Mayor del dinero librado para las obras. Creía el monarca que los citados 1.000 ducados habían sido gastados conforme a lo estipulado en el contrato, pero, para mayor seguridad,

$67 . . . y$ no tener mas de dos pies y medio de grueso y agora a de tener el de la parte de la prision siete pies de grueso y el otro seis pies ... y en el quarto de entre las dos torres $y$ alcaide conbiene ... prosiga el tejado hasta topar en el homenaje de la dicha torre, AGS, Contaduría Mayor de Cuentas III, leg. $1.704, \mathrm{n}^{-}$46, s/f.

${ }^{68}$ La cédula, con otros documentos referentes al mismo asunto, se encuentra en AGS, Contaduría Mayor de Cuentas III, leg. 2.626, no 25, s/f. 
prefería certificar las cuentas ${ }^{69}$. La relación de gastos, con la especificación de las personas que cobraron, así como los materiales, servicios o trabajos realizados, se detallan pormenorizadamente en las cuentas de Castro de Mendoza. Gracias a uno de los pagos consignados tenemos noticia de que Pedro de Llánez fue el arquitecto encargado de llevar a cabo esta nueva reforma, quien cobró por ello los noventa ducados ...en que se taso la obra que hizo en el quarto y torre a donde se havia de mudar el conde de Villalonga, como todo lo suso dicho consta y pareze por la dicha libranza $a^{70}$. Al parecer, los trabajos tenían como finalidad adecuar la prisión para recibir al poderoso Pedro Franqueza, conde de Villalonga. Este personaje, acusado de enriquecerse fraudulentamente aprovechando su cargo de Secretario de Estado con Felipe III, fue juzgado y condenado por sus múltiples abusos, siendo encarcelado en León para expiar sus culpas.

Más tarde, en 1649, los muros y rejas de la fortaleza acogieron al duque de Híjar, sentenciado a reclusión mayor por conspirar contra el rey Felipe $\mathrm{IV}^{71}$. Cuando llegó a su lugar de reclusión fue entregado a Pedro de Quiñones, alcaide del castillo de León, responsable de que cumpliera su condena ${ }^{72}$,

69 ...combenia se trujese raçon y claridad para saber si se habian gastado y consumido todos los materiales que se compraron para efecto de hacerse los dichos reparos, o si habian sobrado y estaban en ser algunos y en poder de que personas... porque Nos sepamos como se cumple nuestro mandado, AGS, Contaduría Mayor de Cuentas III, leg. 2.626, nº 25, s/f.

${ }^{70}$ AGS, Contaduría Mayor de Cuentas III, leg. 2.833, $\mathrm{n}^{\mathrm{o}} 6, \mathrm{~s} / \mathrm{f}$.

${ }^{71}$ La historia de la traición se cuenta en R. EZQUERRA ABADÍA, La conspiración del duque de Híjar (1648), Madrid, 1934.

72 ...bieren como io don Pedro de Quiñones, señor de la casa de Alçedo, castellano del castillo y torres reales desta ciudad de León, guarda mayor del duque de Ixar por su megestad ...en diez y ocho de agosto prosimo pasado deste presente año de cinquenta, ...el señor don Alonso de Nabarra correxidor de ella y su teniente fueron al dicho castillo a ora de mas de las honce de la noche y aviendoles avierto yo la que finalmente devino en perpetua, pues, tras estar encerrado 15 años, murió en la prisión leonesa.

En el año 1652, estando todavía preso el duque de Híjar, el maestro arquitecto Francisco de la Lastra hizo un informe sobre el estado del castillo, especificando las reformas necesarias para mejorar las estancias de la cárcel y los reparos indispensables para su correcto mantenimiento ${ }^{73}$. Entre los más urgentes señala la necesidad de rehacer todos los tejados, tanto los de las torres como los de las demás dependencias; arreglar la escalera de caracol; reparar las maderas de los suelos para evitar el deterioro del enladrillado; intervenir en las caballerizas para subsanar problemas en la estructura y hacer de nuevo los pesebres. El coste total de las obras alcanzaría, según el informe del maestro, dos mil reales, siendo urgente el inicio de los trabajos, pues si llegase el ...ybierno sin acer el reparo se seguira gran ruina y ara de daño dos tantos mas y no se podra avitar con las aguas y niebes ${ }^{74}$.

Las referencias documentales acerca del castillo concernientes al siglo XVIII son prácticamente inexistentes. Es muy posible que poco después de 1700 fuera abandonado, al considerarse innecesario para la nueva época que se abría. Hay que tener en cuenta que con la instauración de la nueva dinastía de los borbones se hizo una profunda reestructuración de la administración del estado. Así, las antiguas competencias

puerta del dicho castillo como castellano del por decir yban a un negocio tocante al servicio de su magestad la primera cosa que ycieron en entrando en el fue tomarme xuramento para que declarase que guardas tenia para la custodia y guarda del duque de Ixar y quantas avia y como se llamavan, Archivo Histórico Provincial de León (desde ahora AHPL). Protocolos de José de Ferreras, caja 233, leg. 360 , fols. 211-214

${ }^{73}$ Sobre la actividad de este arquitecto trasmerano en la provincia de León, véase, E. MORAIS VALLEJO, Aportación al barroco..., p. 68.

${ }^{74}$ AHPL Protocolos de Juan García Zurita, caja 219, fol. 403 . 
del alcaide o tenente del castillo, fueron asumidas por los nuevos cargos creados en el siglo, entre ellos el de Intendente. Por otro lado, tampoco la misión militar o política de León era relevante en la España de la época, con el estado centralizado propugnado por el nuevo monarca. Por todas estas razones, además de la antigüedad del edificio y su costoso mantenimiento, no sería de extrañar que se abandonara a su suerte cuando perdió sus funciones específicas.

Al iniciarse el siglo XIX se encontraba en un estado lamentable, cercano a la ruina y por lo tanto con escasa utilidad. No obstante, el Ayuntamiento de León decidió aprovechar el edificio, que todavía conservaba estructuras sólidas, y se consideraba válido para ciertas actividades de uso público. Además, atesoraba un indudable valor patrimonial que aconsejaba su protección y conservación, impidiendo la pérdida definitiva de un monumento histórico decisivo en la vida de la ciudad.

El Ayuntamiento leonés pensó desde un principio en su acondicionamiento como presidio, encargando al arquitecto municipal, que entonces era Fernando Sánchez Pertejo $^{75}$, la realización de un proyecto para convertir el legendario edificio en cárcel pública $^{76}$. Los castillos, por su propia constitución, tienen las condiciones requeridas para servir de penal, por eso fue bastante común en la época la conversión en presi-

\footnotetext{
${ }^{75}$ Fernando Sánchez Pertejo debió ser designado arquitecto de la ciudad de León a finales del año 1794, pues el 4 de enero de 1795 se leyó una carta en la Junta ordinaria de la Real Academia de Bellas Artes en la que aquel comunicaba su reciente nombramiento con aprobación del Consejo, teniendo la plaza una dotación de 400 ducados, Archivo Real Academia de San Fernando (desde ahora AASF), libro 3/86, fol. 3.

${ }^{76}$ La cárcel de nobles ubicada en el castillo había convivido con la cárcel pública, dedicada al pueblo, que estuvo primero al lado de Puerta de Arco y después en una parte de los palacios reales.
}

dio de muchos castillos españoles ${ }^{77}$. La idea hay que entenderla también dentro del pensamiento romántico, hasta el punto de que la construcción de prisiones, junto con los hospitales o los psiquiátricos, fue una actividad destacada de la arquitectura decimonónica, preocupada por la higiene mental de los ciudadanos y de la socie$\mathrm{dad}^{78}$. La intención era doble, por un lado se quería dar una función eficiente al monumento, que sirviera para su mantenimiento; por otro lado se solucionaba un grave problema de la ciudad que se consideraba urgente, sustituir la obsoleta cárcel antigua. Ésta estaba ubicada en los palacios reales, otro edificio histórico destartalado, viejo e insalubre, según se desprende de múltiples informes realizados en aquellos años ${ }^{79}$.

Sánchez Pertejo hizo un borrador con su idea de convertir el castillo en presidio, lo que abarataría considerablemente el coste de las obras. A él se adosaría un edifico anejo para funciones administrativas y de vivienda, con tres plantas. En la baja se situaría la portada de acceso, acomodando aquí la fachada principal del presidio.

Una vez terminado el diseño, en febrero de 1801, fue enviado al secretario de la Real Academia de Bellas Artes de San Fernando, Isidoro Bosarte ${ }^{80}$, con el fin de que lo examinara informalmente e indicase

\footnotetext{
77 R. MAS HERnÁNDEZ, La presencia militar en las ciudades, Madrid, 2003, p 171.

${ }^{78}$ J. ARRECHEA MigUel, Arquitectura y romanticismo. El pensamiento arquitectónico en la España del siglo XIX, Valladolid, 1989, p. 244.

${ }^{79}$ En los documentos municipales de principios de siglo XIX aparecen en varias ocasiones las obras que se deben hacer para adecentar la cárcel, véase por ejemplo, AHML, Sección de Obras, caja 721, no 16.

${ }^{80}$ Isidoro Bosarte fue Secretario de la Academia desde enero de 1792 hasta su fallecimiento en abril de 1807. Cfr. M. P. García Sepúlveda y E. NAVARRETE MARTÍNEZ, Relación de Miembros pertenecientes a la Real Academia de Bellas Artes de San Fernando (1752-2004), Madrid, 2005, p. 79.
} 
las correcciones pertinentes antes de enviar el proyecto definitivo, asegurándose de esta manera su aprobación ${ }^{81}$. La Junta ordinaria de la Academia de 26-III-1801 sometió a censura ...quatro planos en borrador que ha executado para construir una cárcel, al menor costo posible, en el castillo de la Ciudad de León aprovechando de él todo lo posible. La comisión aprobó estos borradores ${ }^{82}$. Cuatro días después Silvestre Pérez, vicesecretario de la Academia $^{83}$, daba cuenta de la decisión de los académicos ${ }^{84}$, y el 11 de abril del mismo año se comunica la decisión al arquitecto municipal, previniéndole para que hiciera algunas modificaciones en aras de lograr mayor simplicidad y pudiera aprobarse sin mayores contratiempos ${ }^{85}$.

Paralelamente a las actuaciones seguidas con el proyecto en la Real Academia de Bellas Artes, el Ayuntamiento hizo algunas gestiones para conseguir también autorizaciones en otras instancias. El 5 de junio de 1801 la corporación municipal comisionó al procurador general para que

81 ...Muy señor mio de mi mayor estimación: en cumplimiento de la carta orden de esa Real Academia de San Fernando de 2 de agosto que VS se sirbio comunicarme remito los adjuntos diseños en borrador del tamaño que determino ponerlos en limpio de la idea de una cárcel que intentan construir al menor coste posible por repartimiento de entre los vecinos de esta provincia en el castillo de esta capital, AASF, leg. 28 - 2/1, no 3, s/f.

${ }^{82}$ AASF, libro 3/139, fol. 324r

83 Silvestre Pérez, Académico de Mérito desde 1790, fue Vicesecretario de la Academia desde julio de 1799, llegando a ser Director de arquitectura en mayo de 1812, honor que desempeñó hasta su muerte en 1825. Cf. M. P. García SEPúlveda y E. NAVARrete MARTÍNEZ, ob. cit., p. 311.

${ }^{84}$ La Comisión de Arquitectura en su junta de 26 del corriente ha examinado los quatro planos en borrador que ha remitido a censura ...y ha aprobado estos borradores de Pertejo, AASF, leg. 28 - 2/1, nº 3, s/f.

${ }^{85}$ La Academia después de reconocidos atentamente estos diseños ha tenido a bien de aprobarlos pero ha acordado que se prevenga a VM que al tiempo de ponerlos en limpio haga de menor diámetro la luz o vano de la ventana del tímpano del frontispicio y que asimismo aligere los adornos que se demuestran sobre la puerta principal, AASF, leg. 28 $-2 / 1, n^{\circ} 3, \mathrm{~s} / \mathrm{f}$. hiciera el borrador del informe que se había de remitir al Consejo de Castilla junto con los planos del arquitecto de la ciudad ${ }^{86}$.

Los trámites administrativos eran siempre lentos, y con esta obra no hubo una excepción. No tenemos ninguna noticia nueva hasta dos años más tarde, en abril de 1803, cuando la Comisión de arquitectura de la Academia analiza el expediente de la ciudad de León. El informe iba acompañado de los planos realizados por Pertejo, las condiciones de la obra y la regulación del coste estimado de los trabajos ${ }^{87}$. La Comisión debía determinar si era necesario modificar alguna cosa, o si por el contrario daba su aprobación definitiva ${ }^{88}$. Finalmente el proyecto fue aceptado en la Junta Ordinaria de 28 de abril de $1803^{89}$. Inmediatamente Silvestre Pérez comunicó la decisión a León ${ }^{90}$. Con posterioridad, en mayo del mismo año, la Comisión escribió a Bartolomé de la Dehesa informándole que

la Real Academia de San Fernando ha reconocido los 4 diseños, informe $y$ avance que VS me remitió de acuerdo del Consejo con oficio de 19 de abril anterior, executados por el arquitecto aprobado Dn. Fernando Sánchez Pertejo con el fin de habilitar el castillo antiguo de la ciudad de León y destinarlo para cárcel pública y habiendo hallado arreglados dichos diseños se ha servido aprobar completamente el proyecto de Pertejo y la regulación

${ }^{86}$ AHML, Actas Municipales, caja 97, no 96, s/f

${ }^{87}$ La Academia tenía potestad para hacer el visado que era necesario para la correspondiente aprobación de los presupuestos de las obras, cfr. A. MUÑOZ CO$\mathrm{SME}$, La conservación del patrimonio arquitectónico español, Madrid, 1989, p.17

${ }^{88}$ AASF, leg. 28 - 4/1, no 5, s/f.

89 ...en vista de que estos diseños estaban conformes con los borradores que el Arquitecto Pertejo remitió antes confidencialmente a la Academia para su censura, y que aprobó la misma Comisión en su junta de 26 de Marzo de 1801 con algunas prevenciones, repitió ahora en ellos la completa aprobación del Proyecto de Pertejo, y la regulación de su coste, 213.814 rs. 20 mrs. vellon, AASF, libro 3/139, fol. $359 \mathrm{r}$.

${ }^{90}$ AASF, leg. 28 - 4/1, no 5, s/f. 
de su coste. Lo que por acuerdo de la Academia en su junta mensual de $1^{\underline{o}}$ del corriente participo a Vs con devolución de los planos aprobados, informe y avances ${ }^{91}$.

Según se indica aquí, los planos fueron devueltos y por eso, desgraciadamente, no se conservan hoy en su archivo; al no encontrarse tampoco en el archivo del ayuntamiento de León, tenemos que dar por perdidos los dibujos del proyecto.

A pesar de haber conseguido las autorizaciones pertinentes y del interés que parecía tener el Ayuntamiento en disponer cuanto antes de una nueva cárcel, los trabajos de adecuación del edificio militar a otro penitenciario no comenzaron inmediatamente, más bien al contrario, se dilataron en el tiempo de manera incomprensible hasta fechas muy posteriores. No se saben las razones de tal demora, pues no quedaron registradas en la documentación municipal existente. Aventuramos una posible incapacidad financiera, porque no parece consistente cualquier otra razón a la vista de los prolegómenos. Unos años después sucedió un hecho que alargaría todavía más el inicio de los trabajos, se desencadenó la Guerra de la Independencia contra los franceses, que sin ningún lugar a dudas fue determinante para la paralización del proyecto, aunque no para su olvido, como veremos más adelante. No tenemos noticias de que durante la contienda la fortaleza tuviera ningún episodio bélico de interés; es probable que su deterioro le hiciera vulnerable y de escaso valor estratégico para la guerra $^{92}$.

La próxima noticia que disponemos es de 1836. Ese año hay una reactivación del asunto. Los munícipes parecen contraria-

\section{-}

91 AASF, leg. 28 - 4/1, no 5, s/f.

${ }^{92}$ Los aspectos más relevantes de la guerra, sin hacer especial mención del castillo, los trata P. GARCÍA GUTIÉRREZ, La ciudad de León durante la Guerra de la Independencia, Valladolid, 1991. dos, pues tres veces se habían formado planos, cálculos y condiciones para colocar la cárcel pública en el castillo de la ciudad, siendo aprobados una vez por el Consejo de Castilla y Real Academia de San Fernando, y las otras dos por las Diputaciones provinciales, a pesar de lo cual todavía no se habían iniciado las obras ${ }^{93}$. Además, el arquitecto municipal, que sigue siendo Fernando Sánchez Pertejo, propone también, para abaratar los costes, la utilización del edificio anexo, que era el desamortizado convento de Franciscanos Descalzos. La medida, además, tendría el beneficio conservarlo con titularidad pública, antes de que se vendiese o fuera demolido, como algunos ya habían propuesto. Anima a solicitar la cesión, pues, aunque ahora no sea fácil construir dicha cárcel, tendrán dado este paso para lo sucesivo ${ }^{94}$. A continuación hizo la petición a la Junta de edificios de conventos suprimidos, argumentando que así se podría hacer un presidio más amplio, con una mejor división de las estancias, permitiendo independizar totalmente la diferencia de sexos entre los presos, hacer algunas habitaciones para el juez, así como otras estancias necesarias para el buen funcionamiento del centro ${ }^{95}$. La sugerencia del arquitecto no fue atendida y el espacio conventual no pasó a formar parte del presidio en la resolución final.

Otros sucesos históricos paralizaron posteriormente la pretendida adaptación del monumento. Los movimientos militares de las tropas enfrentadas en la Guerra Carlista afectaron a León, de manera que en 1837 se acordó mejorar la fortificación de la ciudad con el fin de protegerse mejor de un posible ataque de los contrarios a la reina Isabel. En esta disposición entraba, como era lógico suponer, el castillo, olvidándose

${ }^{93}$ AHML, Sección de Obras,caja 721, no 16, s/f.

${ }^{94}$ AHML, Sección de Obras, caja 721, no 16, s/f.

${ }^{95}$ AHML, Sección de Obras, caja 721, nº 16, s/f. 
entonces de su reconversión. Las obras realizadas con tal motivo fueron en su mayor parte exteriores a la muralla, o en todo caso adiciones de escaso valor estructural, que han desaparecido en la actualidad. Se abrió un expediente en marzo del citado año en el que se informaba de las medidas para fortificar la ciudad, a fin de lograr una defensa efectiva ${ }^{96}$.

La Capitanía General de Castilla la Vieja dio instrucciones concretas para que se cerrasen todas las salidas de la muralla, excepto las puertas que fueran de absoluta necesidad para las comunicaciones, pero cuidando que estas fueran las situadas en los puntos del recinto que tuvieran mejor defensa. Entre estas, indudablemente, se contaba Puerta Castillo. Asimismo se daban instrucciones para hacer una serie de elementos exteriores con la finalidad de mantenerse al abrigo de los ataques que pudieran hacer los enemigos con artillería. El encargado de diseñar el proyecto y formar el presupuesto correspondiente fue de nuevo Fernando Sánchez Pertejo ${ }^{97}$. Los elementos levantados para el refuerzo del castillo pueden verse en el dibujo realizado por Francisco Marrón en 1840, concretándose en un espolón delante del murallón y un recinto poligonal para proteger Puerta Cas-

96 ...se manda por el articulo $3^{\underline{o}}$ de la Real Orden de 17 del corriente concebida en estos términos "Que invoque VE en el animo de los Ayuntamientos de los pueblos, que estos busquen también su apoyo dentro de su recinto mediante fortificaciones pasageras, convocando a todos los milicianos de su partido e imitando el noble ejemplo de Requena, Quintanar, Siruela y otros que han resistido con gloria a las momentáneas irrupciones de las bandas facciosas y salvado sus hogares, AHML, Expediente general de fortificación, Gobierno Político de la Provincia de León, caja 716, nº 1 , $\mathrm{s} / \mathrm{f}$.

${ }^{97} 115.389$ reales vellon que será lo que poco más o menos podrán costar las referidas obras de fortificación; cuyo cálculo he formado con la premura que V S me encarga en su oficio de hoy. Dios guarde a V S muchos años. León y mayo 10 de 1837. Fernando Sánchez Pertejo, AHML, caja $716, \mathrm{n}^{\mathrm{o}} 1$, s/f. tillo $^{98}$ (fig. 3). El plano tiene muy pocos detalles, por lo que no podemos saber el material utilizado ni su estructura, o la altura de las defensas, tan sólo que su diseño era angular, siguiendo las directrices de la poliorcética recogida en los tratados militares de la época, para contrarrestar mejor los ataques artilleros. Nada ha quedado en pie de estas obras, salvo su memoria en algunos documentos.

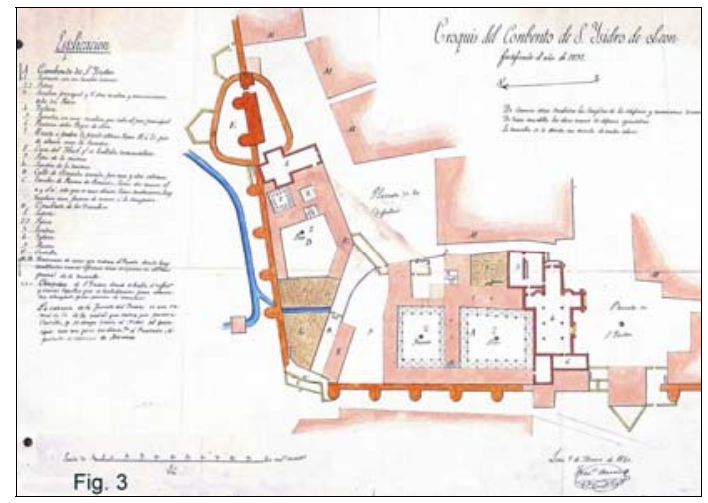

Terminado el conflicto, se vuelve a la idea de hacer la prisión en el castillo. En aquellos momentos el antiguo penal seguía ubicado en los antiguos palacios reales, en unas condiciones pésimas, siendo urgente su remodelación tanto por higiene como por el peligro de ruina inminente que corría. La Junta de la cárcel de León, en su reunión de 12 de enero de 1853, trató sobre la posibilidad de hacer una nuevo penal y se vio una comunicación del Sr. Gobernador acompañada de un proyecto de refecciones para la cárcel vieja. A la vista del escrito, la Junta acuerda contestar que es inútil hacer desembolsos de consideración en dicho establecimiento, porque todo lo que no sea hacer una cárcel de nueva planta

${ }^{98}$ Francisco Marrón, Croquis del Conbento de S. Ysidro de León fortificado en el año de 1837, Servicio Histórico Militar, Le - M 1/12; publicado por F. ALONSO GARCíA, León en la cartografía histórica, Madrid, 1996, p. 93. 
no remedia el mal y se convierte en un gasto inútil. Se aprovecha la ocasión para recordar que en la construcción de la nueva debe contribuir el estado, la provincia y el partido $^{99}$.

El tiempo pasa y el proyecto no se activa, lo cual no es de extrañar a la vista de la inestable situación política de España, que en pocos años vive el derrocamiento de Isabel II, la Revolución de la Gloriosa y el reinado de Amadeo I de Saboya. En agosto de 1871 se aborda otra vez el tema, viéndose un oficio del Sr. Juez de $1^{\underline{a}}$ Instancia del Partido en el que encarece la necesidad de buscar un local para la Cárcel y Sala de Audiencia, porque el existente carecía de las mínimas condiciones de salubridad. La Junta examinó un presupuesto hecho por el arquitecto municipal para su reforma, de modo que pudiera utilizarse por algún tiempo más hasta la inauguración de la nueva; acordaron aprobarlo debido a la urgencia de la ejecución, pero a sabiendas de que era una solución de trámite y nunca definitiva ${ }^{100}$

Por fin, el Ayuntamiento emprendió las obras para reformar el castillo y ubicar en él la cárcel común del partido judicial de León, pero los trabajos no fueron rápidos y hubo periodos de inactividad. En uno de ellos se pidió la cesión de la obra para habilitarla con destino a enfermería de coléricos, petición que fue denegada ${ }^{101}$.

Hay que ir hasta febrero de 1876, en el reinado de Alfonso XIII, para encontrar a

99 ...porque en la cárcel de la capital no se custodian sólo los presos que dependen del juzgado de $1^{\underline{a}}$ Instancia sino también los de la Hacienda y Tribunal Militar, AHML, caja $121, \mathrm{n}^{\mathrm{o}} 255$.

100 ...y se acuerda que se conteste manifestando que es inútil hacer gastos de consideración en dicho establecimiento porque todo lo que no sea hacer la cárcel de nueva planta no es remediar el mal, AHML, caja 121, oㅡ 255 .

101 J. Eguiagaray, León y la tragedia de D. Pedro Balanzategui Altuna, León, 1969, p. 67. la Junta de la Cárcel de León examinando el presupuesto y las condiciones formulados por el arquitecto Francisco J. Daura, con el fin de reanudar la construcción suspendida, ascendiendo el cálculo a casi 27.000 pesetas ${ }^{102}$. Una nueva Junta, en septiembre del mismo año, dio cuenta de las obras ejecutadas en el edificio, así como de las que faltaban; entre éstas destacaba la cubrición de todo el edificio o la conveniencia de contraer un empréstito para tener liquidez. También se leyó una extensa y razonada memoria presentada por el director de las obras, en la que notificaba los trabajos ejecutados $\mathrm{y}$ pagados, los que faltan por concluir y cual sería su importe. Asimismo, el informe ponía de relieve la necesidad de ampliar y ejecutar cuanto antes las obras, pues de otro modo se inutilizarían las hechas hasta el momento. Todas las indicaciones fueron aprobadas después de su discusión, incluida la solicitud de un préstamo con objeto de afrontar los pagos más necesarios ${ }^{103}$. Las obras se prolongaron hasta 1877, cuando se dio por concluida definitivamente la reconversión en presidio.

El viejo edificio de la calle de la Rúa, donde estuvieron los antiguos palacios reales y se ubicó la cárcel pública desde el

${ }^{102}$ Vistos el presupuesto y condiciones formulados por el arquitecto Sr. Daura para emprender de nuevo la construcción suspendida de la cárcel, cuyos documentos se refieren no al total de la obra que aun falta por ejecutar sino a una porción de ella, ascendiendo dicho presupuesto a veinte y seis mil nuevecientas veinte y ocho pesetas, siete céntimos, se aprueban y acuerda que se anuncie la subasta de dicha obra cuanto antes ... se acuerda también que se saquen de la caja de depósitos las cantidades en ella existente y destinada a la construcción de la cárcel, AHML, caja 121, no 255 .

103 ...facultando igualmente al Sr. Presidente para contratar un empréstito bajo las condiciones que se formularán y aplicando a su amortización de capital y pago de intereses la cantidad anual que satisfaga el Partido con destino a la terminación de las obras, ofreciendo también en garantía si fuese posible el valor de la cárcel vieja, AHML, caja 121, no 255. 
siglo $\mathrm{XVI}^{104}$, estuvo en pie hasta 1881 , cuando la Junta de Cárcel del Partido de León, en la sesión ordinaria del día 19 de noviembre, decidió por fin demolerlo debido a que su estado ruinoso hacía imposible su rehabilitación ${ }^{105}$.

Una vez finalizada la empresa, quedó acondicionada la prisión en las antiguas dependencias y en una edificación de nueva planta adosada a la parte trasera del castillo. No estamos en disposición de confirmar si se llevó a cabo el proyecto inicial de Fernando Sánchez Pertejo, varias veces aprobado como vimos más arriba, o si por el contrario se hizo otro nuevo, relacionado mucho o poco con el primitivo. El arquitecto Daura, mencionado en la documentación como director de la obra en su última fase, pudo haber introducido algunas mejoras teniendo en cuenta los años que pasaron entre los primeros borradores de principio de siglo y los últimos trabajos realizados casi 80 años después.

Las celdas se acomodaron en los espacios habilitados en el interior de los cubos y en las estancias creadas al recrecer la muralla. Probablemente a esta época pertenezca la construcción de la última planta entre las torres semicirculares, realizado por completo en ladrillo. La rehabilitación también afectó a los cubos, como se comprueba en las tongadas de ladrillo yuxtapuestas al aparejo de piedra.

-

${ }^{104}$ En 1536, en tiempos de Carlos I, se trasladó la cárcel pública a unas dependencias de los palacios reales, como se recoge en varios documentos, por ejemplo, AHML, caja 17, no 525, s/f: ...la carçel publica de esa ciudad siempre estubo en el medio della a do dizen Puerta del Arco ... e que ansi era que el corregidor pasado diziendo que hera penosa y mal segura la mando por en propia authoridad podiendolo remediar a muy poca costa $y$ diz que la puso y asento en los palaçios que dizen del rey en parte donde los presos estan muy apretados y apartados de las gentes y no tan seguros como deven estar e nadie no los vee de que reçiben mucho daño ...

105 AHML, caja 121, nº 255.
Mantuvo su función penitenciara hasta 1960, cuando se inauguró una cárcel hecha de nueva planta a las afueras de la ciudad, donde se trasladaron las dependencias carcelarias en su totalidad. El castillo quedó otra vez abandonado y destartalado, pero como todavía conservaba una estructura sólida que podía ser útil, muchas voces locales reclamaron su aprovechamiento como edificio público, que supliera alguna de las carencias de la ciudad, y preservar de esta manera un documento de indudable valor histórico para la ciudad.

Por fin, hacia 1976 se iniciaron las gestiones para adecuar el monumento como Archivo Histórico Provincial de León. El nuevo proyecto de transformación lo realizó Eduardo González Mercadé en 1978 con un presupuesto inicial de 94.025.248 pesetas $^{106}$. Su idea, como consta en la memoria que redactó para la ocasión, era seguir las recomendaciones del Consejo de Europa para la conservación y revitalización del patrimonio arquitectónico, dotando de un nuevo uso al edificio monumental para conseguir su mantenimiento. Además, en su proyecto declara que tendrá en cuenta el decreto de 3 de junio de 1931 por el que se declaraba Monumento Histórico Artístico Nacional al recinto de las murallas de León, así como el decreto de 22 de abril de 1949 por el que se proclamaron todos los castillos españoles protegidos por el Estado, y el decreto de 5 de septiembre de 1962 por el que se reconocía como Conjunto Histórico Artístico a toda la zona comprendida dentro de la muralla romana de León. El arquitecto expone como principio rector de su actuación la intención de conservar a ultranza el conjunto de los volúmenes del inmueble, pero haciendo una redistribución

${ }^{106}$ El proyecto se encuentra en AHPL, Fondo documental del AHPL, Memoria de las obras de restauración y adecuación del antiguo Castillo de León para Archivo Histórico Provincial, cajas 1 y 2. 
de los interiores para adecuarlo a las necesidades propias de un archivo ${ }^{107}$. De ahí que procediera a vaciar por completo los cubos y las estancias levantadas sobre la muralla, haciendo la demolición completa de forjados, paredes y demás divisiones, hasta lograr un espacio sólo definido por los muros periféricos, como se puede ver en fotos de la época. Su intención, que finalmente se ejecutó, era hacer una ordenación completamente nueva de los espacios interiores, manteniendo inalterada la fisonomía exterior. De esta manera el castillo, para un espectador externo, seguiría teniendo prácticamente las mismas formas que dejó la restauración y ampliación de principios del XIX. Con este procedimiento se perdieron las estructuras originales, además de importantes elementos arquitectónicos e históricos, imprescindibles para la comprensión global del edificio y para reconstruir su historia. Ahora, una estructura mixta de hormigón y acero, independiente de los muros de mampostería y ladrillo, sostiene los más de $10 \mathrm{kms}$. de estanterías que contienen los documentos ${ }^{108}$. González Mercadé actuó de la manera que suele ser habitual en estos tipos de edificios, manteniendo las fachadas y edificando tras ellas un interior que nada tiene que ver con el original; eliminando la organización arquitectónica que le dio su razón de ser, conservó su fisonomía, pero se perdió la memoria de sus usos anteriores ${ }^{109}$. La reconversión del edificio se inauguró en 1982. Poco después, en 1985, Javier Olivié Vaca-Arrazo hizo una

\footnotetext{
${ }^{107}$ AHPL, Fondo documental del AHPL, caja 1, p. 13.

108 AA VV, León. Casco Antiguo y Ensanche. Guía de arquitectura, León, 2000, p.77.

${ }^{109}$ Este tipo de restauración es muy criticada en la actualidad porque se considera que actuando así el monumento se destruye, y lo que queda es una engañosa escenografía, véase por ejemplo A. CAPITEL, "Inmueble monumental y forma urbana", en 50 años de protección del Patrimonio histórico-artístico, 1933-1983, Madrid, 1983, p. 22.
}

intervención que tenía como principal objetivo la conservación y mejora del aspecto exterior, pero sin afectar a las estructuras del castillo.

Posteriormente se han realizado diversos trabajos de restauración, mejora $\mathrm{y}$ ampliación del archivo, que solamente reseñamos y no entramos en su análisis por sobrepasar los límites de nuestro trabajo.

La vieja pretensión de Sánchez Pertejo, aunque con función distinta, se ha cumplido. La antigua iglesia del convento de los Franciscanos Descalzos ahora forma parte del Archivo, ocupando su espacio nuevos anaqueles para ampliar la capacidad de almacenamiento documental. El proyecto de anexión lo realizó Manuel Manzano Monís en el año 1990.

La última intervención se debe a Francisco J. González, que en 1999 diseñó una nueva reforma, inaugurada en 2003. Su intención consistía en renovar las dependencias archivísticas, por lo tanto, actuando sobre todo en los espacios interiores, a los que pretendía dar una configuración más funcional y moderna, acordes con las necesidades del momento.

En la actualidad los muros del castillo siguen albergando el Archivo Histórico Provincial de León, de manera que el edificio más antiguo de la ciudad que todavía se conserva en pie, por la sólida base romana, sirve para guardar la memoria histórica de León. 


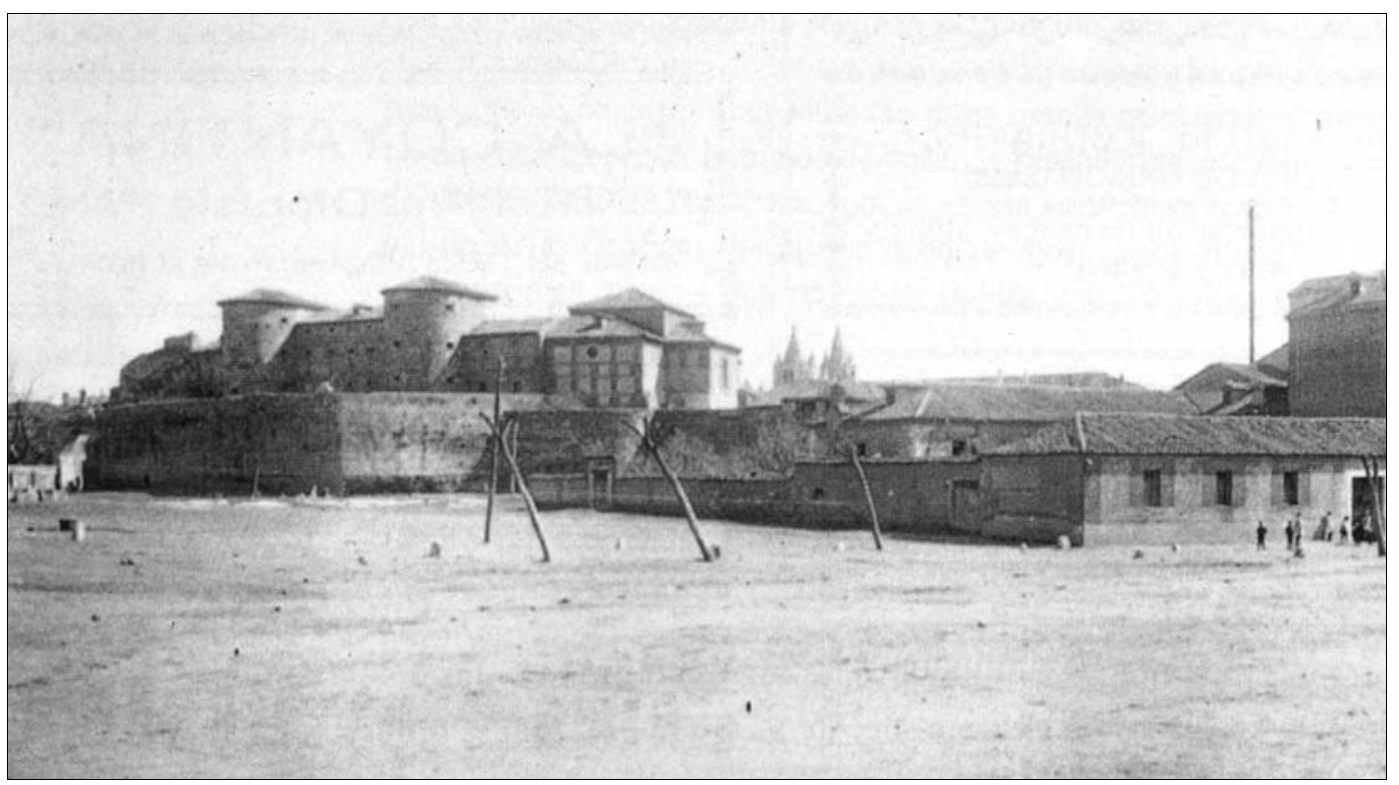

- Lám. 1. Vista general del castillo a principios del s. XX.

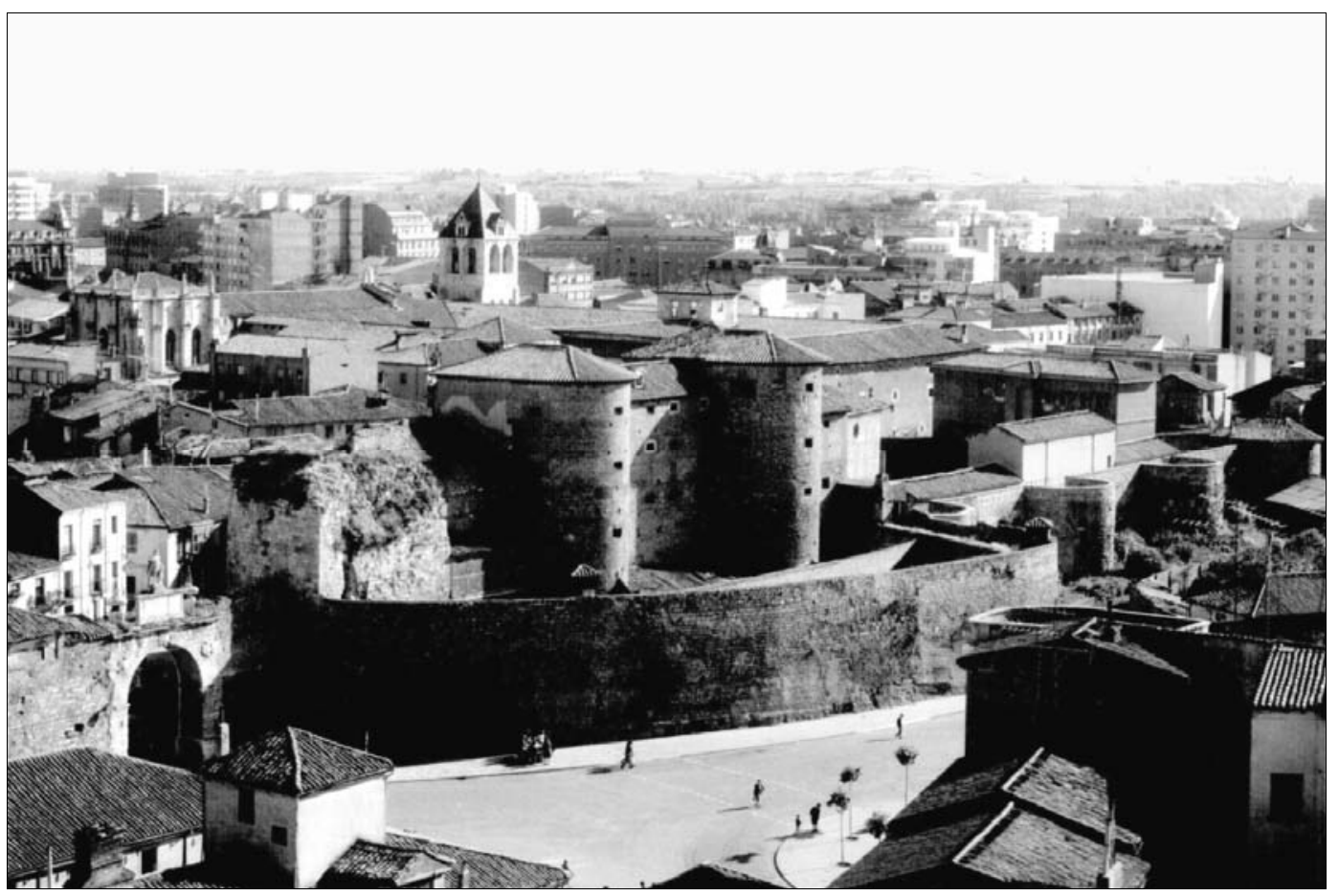

- Lám. 2. Vista aérea del castillo a mediados del s. XX. 


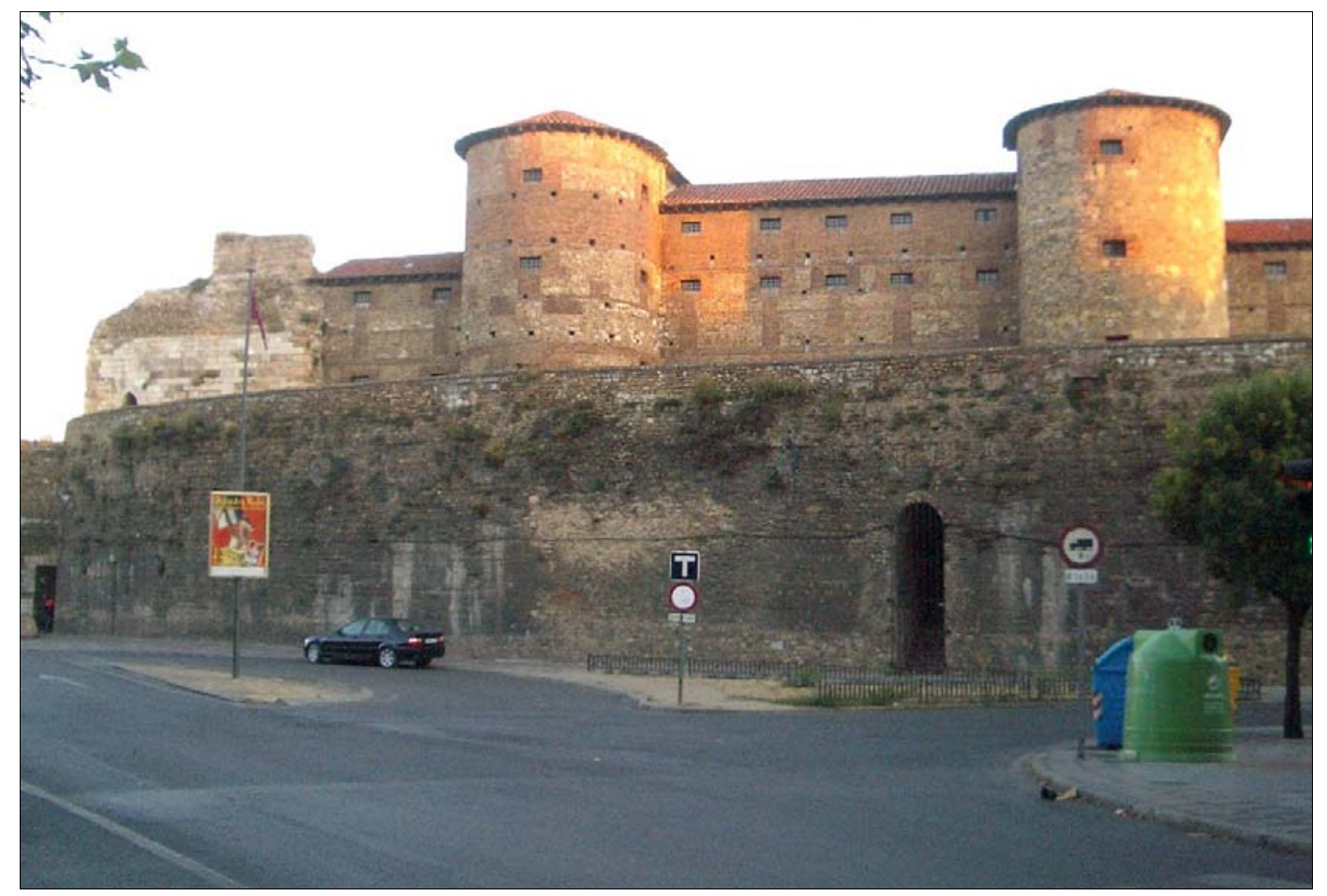

- Lám. 3. Vista actual del castillo.

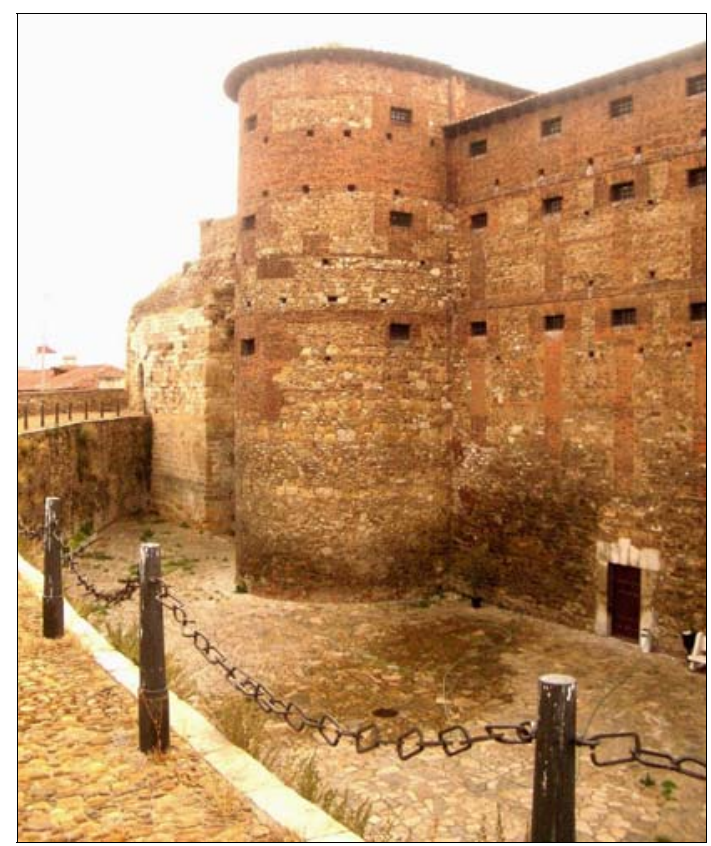

- Lám. 4. Detalle del castillo.

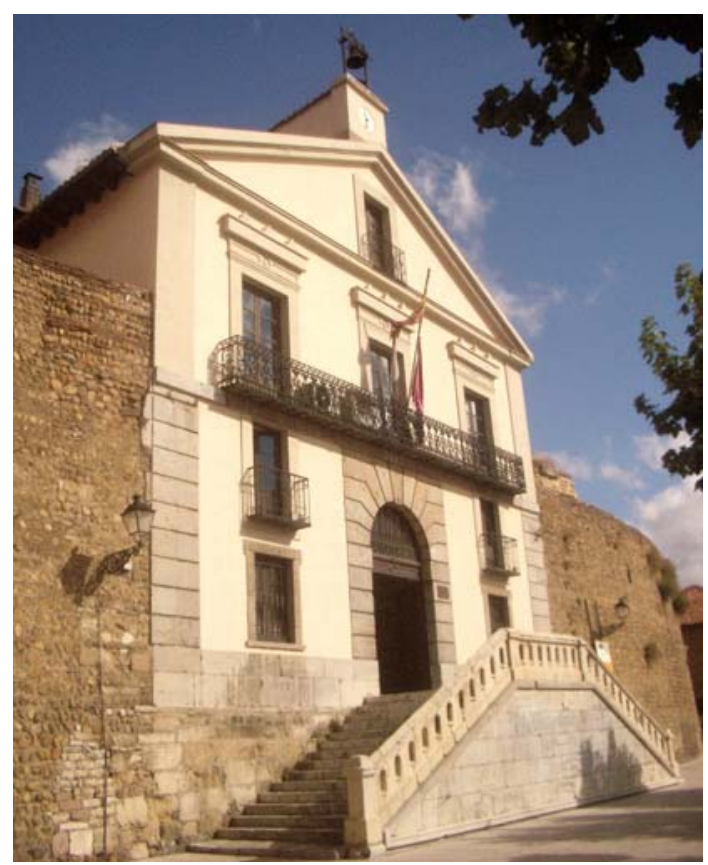

- Lám. 5. Fachada principal de la cárcel. Hoy Archivo Histórico Provincial del León. 


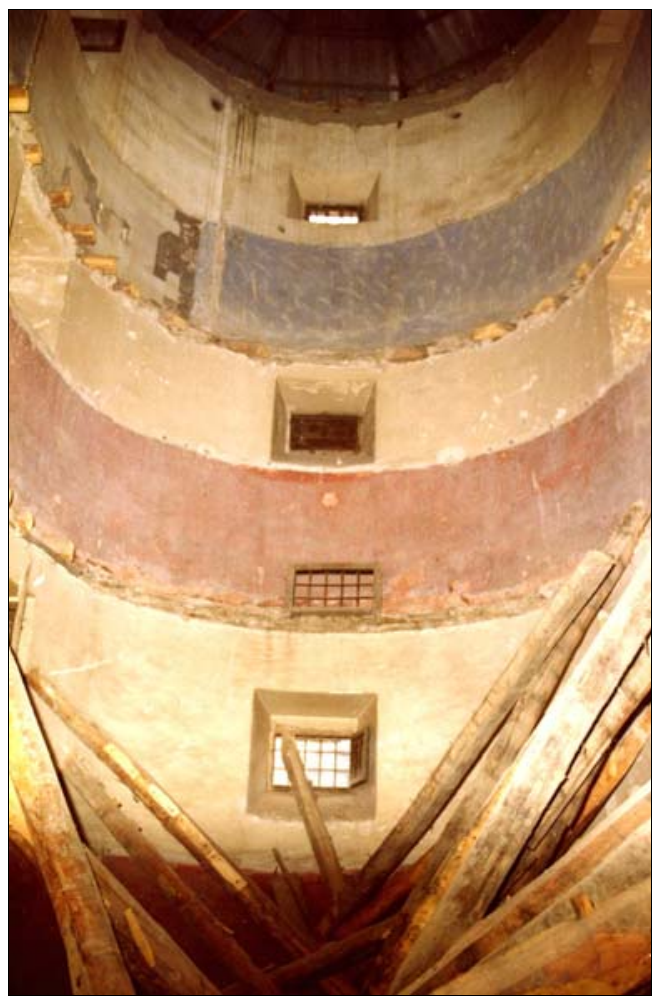

- Lám. 6. Interior de uno de los cubos del castillo, completamente vaciado, antes de hacer las estructuras interiores para acondicionar el Archivo.

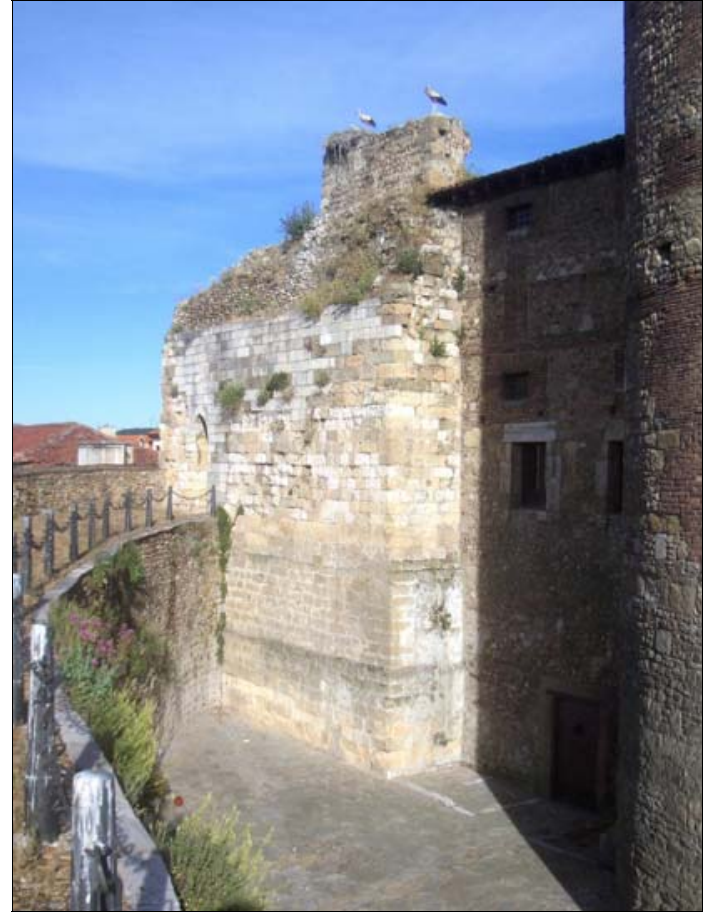

- Lám. 7. Detalle de la torre de sillería del Castillo.

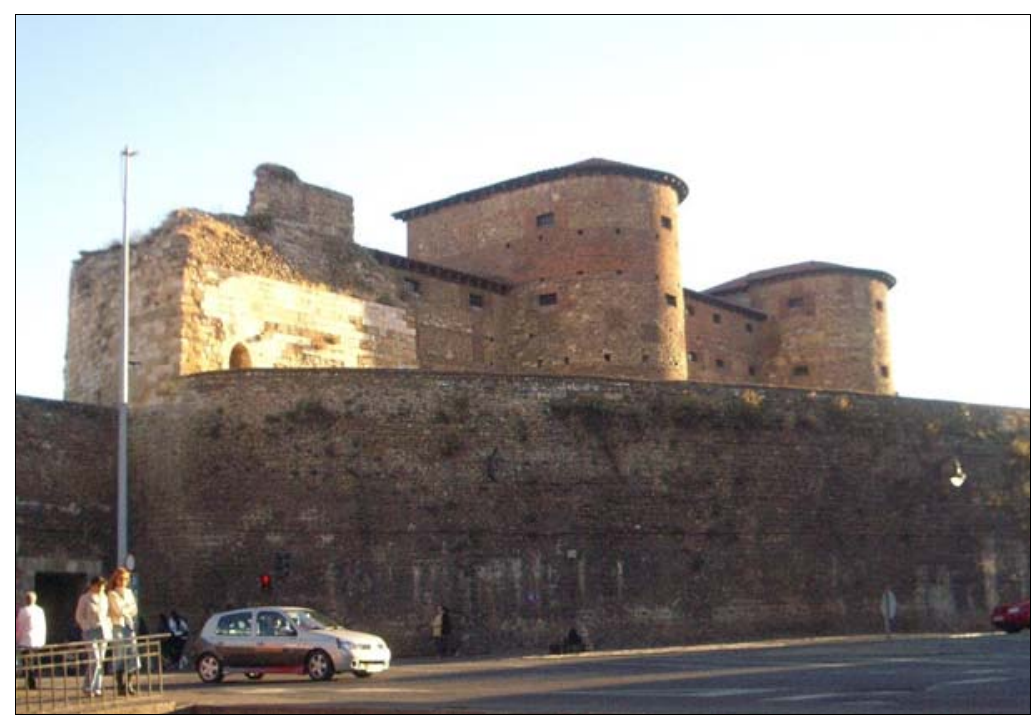

- Lám. 8. Vista general del castillo 